\title{
Evolution of sea-level trends along the Norwegian coast from 1960 to 2100
}

\author{
Kristian Breili ${ }^{1,2}$ [D
}

Received: 14 June 2021 / Accepted: 26 November 2021 / Published online: 22 January 2022

(C) The Author(s) 2022

\begin{abstract}
A first national analysis of the evolution of sea-level rates along the Norwegian coast for the period 1960-2100 has been accomplished by exploring tide-gauge records, relative sea-level projections, and detection techniques for acceleration. Firstly, sea-level rates for the two study periods 1960-2020 and 1991-2020 were estimated. Along the Norwegian coast, relative sea-level rates show significant spatial variation due to glacial isostatic adjustment. Moreover, the coastal average sea-level rate for the period 1991-2020 is significantly higher than for the period 1960-2020. Accelerations were then estimated for all combinations of start years and study periods longer than 30 years by including quadratic coefficients in regression models. It was found that the estimates strongly depend on the study period and do not provide confident estimates of climate change driven variation in the sea level along the Norwegian coast. Secondly, non-linear trends in relative sea level were reconstructed from Singular-Spectrum Analysis, which at several tide gauges revealed low rates in the 1970s, maximum rates around 1990, and declining rates thereafter. From the reconstructed trends, significant positive acceleration in the relative sea level was estimated for the period 1960-2020, while accelerations less than zero were detected for the period 1991-2020. However, the estimates for the recent period appear not robust due to the influence of decadal and multidecadal variation characterizing Norwegian tide-gauge records. Finally, by artificially extending the tide-gauge records by projections, the time when unprecedented high sea-level rates emerge was identified. With projections calculated for the intensive emission scenario RCP8.5, the climate signal of the relative sea level emerges at earliest in the late 2030s. The time of emergence is typically 5 to 10 years later if reanalysis of sea-level pressure and wind speed are used to reduce decadal variation in the tide-gauge records. This is because the meteorological regressors, as a side effect, introduce serial correlations that lead to rate estimates with enlarged standard errors. An important implication of the findings is that a possible absence of record high sea-level rates in the 2020s and 2030s does not falsify that relative sea level along the Norwegian coast is consistent with projections of RCP8.5.
\end{abstract}

Keywords Sea level · Tide gauges · Climate change $\cdot$ Singular spectrum analysis $\cdot$ Norwegian coast

\section{Introduction}

Reconstructions of the global mean sea level have with high confidence indicated that the mean rate of sea-level rise has accelerated during the last two centuries (see, e.g., Church and White (2006), Jevrejeva et al. (2008), Cazenave and Llovel (2010), Haigh et al. (2014), Nerem et al. (2018), and

Kristian Breili

kristian.breili@kartverket.no

1 Geodetic Institute, Norwegian Mapping Authority, 3507, Hønefoss, Norway

2 Faculty of Science and Technology, Norwegian University of Life Sciences, 1432, Ås, Norway
Veng and Andersen (2021)). In a review by Oppenheimer et al. (2019), acceleration estimates of reconstructions of the global mean sea level over the period 1902 to 2010 ranged from -0.002 to $0.019 \mathrm{~mm} / \mathrm{year}^{2}$. From satellite altimetry, Nerem et al. (2018) estimated the climate driven acceleration to be $0.085 \pm 0.025 \mathrm{~mm} / \mathrm{year}^{2}$ over 1993 2017, while Veng and Andersen (2021) estimated the acceleration to be $0.095 \pm 0.009 \mathrm{~mm} / \mathrm{year}^{2}$ from altimetry data covering $\pm 82^{\circ}$ latitude and the period 1991.7-2019 and $0.080 \pm 0.008 \mathrm{~mm} /$ year $^{2}$ with data covering $\pm 66^{\circ}$ latitude and the period 1993-2019. The identified significant accelerations imply that the global mean sea level is an early climate change indicator that is less sensitive to the large internal variability that characterizes the surface temperature record (Fasullo et al. 2016). It is, however, 
more difficult to identify acceleration in records from individual tide gauges because they are prone to decadal and multidecadal variation, measurement noise, and local effects like vertical land motion (VLM) and river runoff. As a consequence, climate signals need more time to emerge in individual tide-gauge records (Lyu et al. 2014; Fasullo et al. 2016; Haigh et al. 2014).

In this study, the evolution of relative sea level (RSL) rates estimated from records of individual tide gauges along the Norwegian coast will be analyzed. The Norwegian coast is about $103000 \mathrm{~km}$ long, spans 13 latitudinal degrees, and has a network of 23 permanently operated tide gauges. The Norwegian network of tide gauges has extensively been used to assess sea-level rise and validate satellite altimetry observations (see, e.g., Richter et al. (2012), Breili et al. (2017), Idžanović et al. (2017, 2019), Ophaug et al. (2021), Breili (2021)). The general agreement reported between altimetry and tide-gauge observations increases the confidence in recent tide-gauge observations from the Norwegian coast.

An important contributor to spatial variation in RSL along the Norwegian coast is VLM, primarily caused by glacial isostatic adjustment (GIA) due to past glaciations of Fennoscandia. The effect of GIA, is evident in RSL rates calculated by Breili et al. (2017), varying between -2.3 and $1.2 \mathrm{~mm} /$ year for the period 1960-2010. Hünicke and Zorita (2016) argued that the acceleration of VLM due to GIA in Fennoscandia is proportional to the present GIA rates by a factor of -0.0002 year $^{-1}$. Hence, it is fair to assume that GIA in Norway is constant on centennial scales and of negligible consequence in computations of acceleration.

Next after GIA, Richter et al. (2012) showed that the largest trend contribution along the Norwegian coast is from the thermosteric component, while the halosteric component has a weak negative contribution, and long-term changes in atmospheric surface pressure are insignificant at most tide gauges. In addition, mass changes on glaciers and changes in land hydrology may partly explain longer-term changes in sea level along the Norwegian coast. Moreover, Richter et al. (2012) and Calafat et al. (2013) found that a considerable fraction of decadal and multidecadal sea-level variability is driven by variation in atmospheric pressure and the steric component. In Calafat et al. (2013), it was demonstrated that the variation in the steric component along the Norwegian coast is remotely driven and coherent with variability in sea level over the North Sea. They suggested that this variation is caused partly by winddriven sea-level fluctuations that propagate along the eastern boundary of the North-Atlantic and partly by the wind over the Faroe-Shetland channel and the Norwegian shelf.

Along the Norwegian coast, projections of future RSL have recently been elaborated (Simpson et al. 2015, 2017). For the most intensive emission scenario (RCP8.5) of the Intergovernmental Panel on Climate Change (IPCC), projected RSL is 0.15 to $0.55 \mathrm{~m}$ higher in 2100 than over 1986-2005. In order to reach these levels, RSL rates calculated for the period 1960-2010 at Norwegian tide gauges (Breili et al. 2017), must accelerate by between 0.05 and $0.08 \mathrm{~mm} / \mathrm{year}^{2}$. However, sustained acceleration in RSL has not been confidently established in individual tidegauge records from the Norwegian coast, although some evidences have been reported. Breili et al. (2017) found that the coastal average sea-level rate corrected for VLM increased from $2.0 \pm 0.6 \mathrm{~mm} /$ year to $3.2 \pm 0.6 \mathrm{~mm} /$ year between the periods 1960-2010 and 1993-2016. Similar results were obtained by Wahl et al. (2013), who analyzed linear trends in records from tide gauges along the NorthSea coastline. For the three Norwegian tide gauges included in their study, they found highest rates for the shortest and most recent study period. It was not concluded whether the observed increase resulted from global warming or was caused by natural variability in the climate system.

We will start our study by computing updated sea-level rates for the two study periods 1960-2020 and 1991-2020 for tide gauges along the Norwegian coast. Then, we will go on and address the detection of the climate signal of global warming in the tide-gauge records. Different techniques for detecting acceleration will be explored. We define the sealevel rate as the annual change in sea level and acceleration as a change in the sea-level rate. Firstly, acceleration in individual tide-gauge records will be estimated by including quadratic coefficients in regression models. Secondly, variation in sea-level rates will be analyzed using SingularSpectrum Analysis (SSA) to decompose the tide-gauge records into its significant and noisy parts with dataadaptive orthogonal filters (Vautard et al. 1992). Non-linear trends of the signal can then be reconstructed from the SSA components and rates can be calculated by differentiating the non-linear trends. Finally, by extending the tide-gauge records into the future by RSL projections, the year when sea-level rates are expected to be significantly higher than those observed in the past will be identified. As part of this study, we will explore a suite of regression models, where tide-gauge observations, meteorological reanalysis, and the North Atlantic Oscillation (NAO) index are combined. We will rank these models individually at each tide gauge with respect to information criteria for model selection and investigate to what extent the regressors of the best-ranked model can be used to reduce decadal variability in the tidegauge records and thereby shorten the time of emergence of the climate signal.

The present study is a novel nationwide study of its type for Norway, addressing past, present, and future evolution of sea-level rates. It is mainly motivated by the need for better knowledge about how the local RSL responds to a warmer climate. This knowledge will help planners 
and coastal managers to prepare for higher RSL, ensure coastal safety, and communicate risks and consequences of higher sea level to stakeholders and the public. Coastal planning is critical because the coastal zones are densely populated areas, have large population growth, and are economically important (Nicholls and Cazenave 2010). Consistency between observations and projections will increase the confidence in the latter and may be used to point out the climate change pathway of sea-level rise. On the other hand, deviations between observations and projections may motivate for revision of the latter. The earlier we identify the pathway of sea-level rise, the better the local communities can adapt to it.

\section{Data and methods}

We have combined tide-gauge records from the Norwegian coast with meteorological reanalysis of atmospheric pressure and wind speed, the NAO index, and regional projections of RSL for the twenty-first century. In order to consistently compare the results from different tide gauges, avoid major data gaps, and maximize overlap with auxiliary data sets, this study will focus on observations from the period 1960-2020. For similar reasons, the same starting point was chosen by Richter et al. (2012) and Breili et al. (2017). The selected study period includes the onset of a steady increase in global temperature and ocean heat content, starting around 1970 and succeeding a flattening in temperature and heat content in the period after approximately 1940 (Hartmann et al. 2013; Rhein et al. 2013). A similar pattern is also seen in the temperature record of Norway (Hanssen-Bauer et al. 2017). Hence, the selected study period overlaps the period of the most rapid increase in ocean and land temperature seen in the instrumental record. In addition, the study period includes a sharp increase in water impoundment by artificial reservoirs, leading to lower-than-average sea-level rates during the 1970s (Frederikse et al. 2020) and a total sea-level fall of approximately $10 \mathrm{~mm}$ over the period 1960-1990 (Hawley et al. 2020).

\subsection{Tide-gauge records}

The Norwegian tide-gauge network consist of 23 tide gauges (see Fig. 1 and Table 1) that provide records of varying lengths, the longest starts in 1873 and the shortest in 1990. The tide-gauge records were downloaded from the Permanent Service for Mean Sea Level (PSMSL) (Holgate et al. 2013) and we chose to use records with annual averages in order to match the sampling rate of the projections. Only revised local reference (RLR) data were analyzed, which are records that are reduced to a common datum achieved by making use of the tide-gauge datum history provided by the supplying authority. The RLR records are free of major offsets, but minor offsets may still exist due to change of equipment, instrumental effects, and missing control leveling between the tide-gauge benchmarks and the contact point of the tide gauges.

The records were screened in order to eliminate time series with significant data gaps. For each record, we required that more than $80 \%$ of the data were available for the period 1960-2020. The record from Trondheim is complete, but the tide gauge was relocated in 1990 and the new location experiences local subsidence of 12 mm/year. Although data after 1990 are corrected for subsidence, older data are encumbered with errors that cannot be quantified and should not be used for time series analysis (Norwegian Hydrographic Service, personal communication, 2021). Hence, we chose not to use data from Trondheim. On the other hand, we have included the record from Rørvik that has its start year in 1969 and is shorter than the other records. It is included because $82 \%$ of the study period is covered by observations from this station, the record has no major data gaps, and it is the only station observing RSL in the vast region between the tide gauges in Heimsjø and Bod $\varnothing$ when Trondheim is not included.

In order to identify anomalous observations and assess the quality of the tide-gauge records, we also executed a buddy check. The buddy check implied that we computed

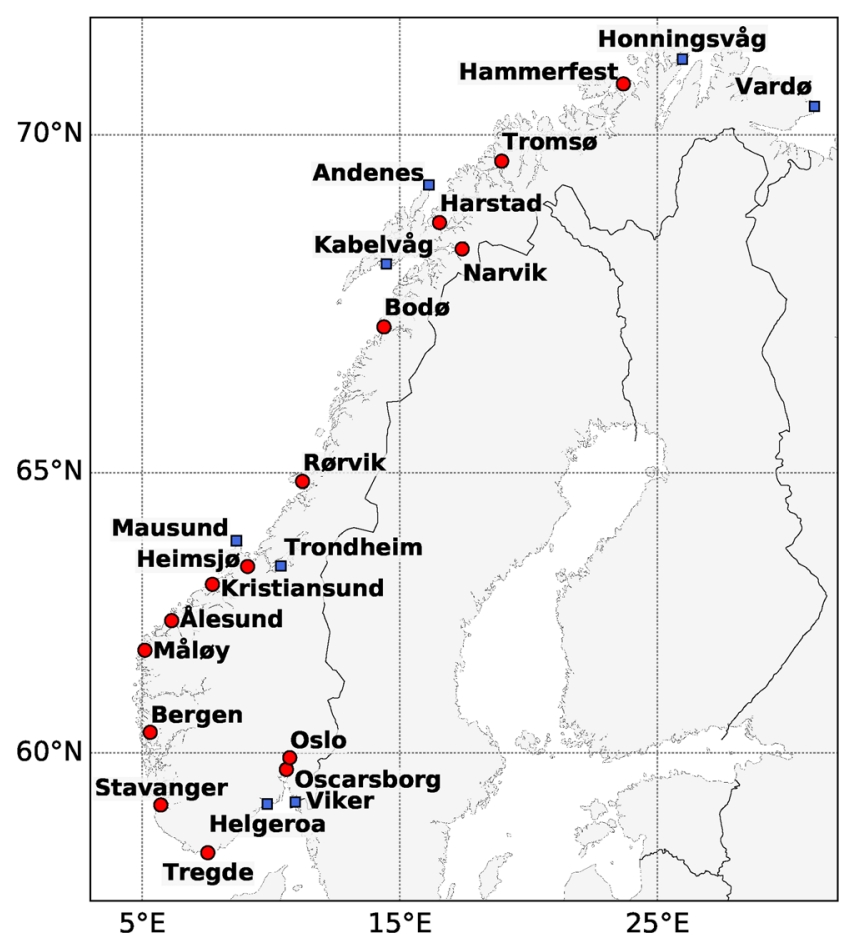

Fig. 1 The network of permanent Norwegian tide gauges. Red filled circles indicate the tide gauges used in the present study while blue filled squares are tide gauges with records that did not pass screening and quality check 
Table 1 Overview of start years and completeness of Norwegian tide-gauge records

\begin{tabular}{|c|c|c|c|c|}
\hline Tide gauge & $\begin{array}{l}\text { Start } \\
\text { of record }\end{array}$ & $\begin{array}{l}\text { Completeness } \\
\text { of record }\end{array}$ & $\begin{array}{l}\text { Missing years } \\
(1960-2020)\end{array}$ & QC \\
\hline Vard $\varnothing$ & 1948 & $64 \%$ & 1963-1983,1990,2001 & Not used \\
\hline Honningsvåg & 1972 & $74 \%$ & $1985,1987-1989$ & Not used \\
\hline Hammerfest & 1957 & $84 \%$ & $\begin{array}{l}1962,1965-1970 \\
1976,1982,1990\end{array}$ & 6 \\
\hline Troms $\varnothing$ & 1953 & $97 \%$ & 1986,1988 & 6 \\
\hline Andenes & 1938 & $56 \%$ & 1960-73,1978-1991 & Not used \\
\hline Harstad & 1953 & $90 \%$ & $\begin{array}{l}\text { 1966,1975-1976, } \\
1980,1988,1990\end{array}$ & 5 \\
\hline Narvik & 1929 & $97 \%$ & 1989,2020 & 5 \\
\hline Kabelvåg & 1948 & $95 \%$ & 1974,1988-1989 & 5 \\
\hline Bod $\varnothing$ & 1950 & $82 \%$ & $\begin{array}{l}1965-1967,1969-1973 \\
1986,1988,1990\end{array}$ & 5 and 4 \\
\hline Rørvik & 1970 & $82 \%$ & $1960-1969,1988$ & 4 \\
\hline Trondheim & 1949 & $100 \%$ & & Not used \\
\hline Heimsjø & 1928 & $95 \%$ & $1965,1973,1990$ & 3 and 4 \\
\hline Kristiansund & 1953 & $97 \%$ & 1986-1987 & 3 \\
\hline Mausund & \multicolumn{3}{|c|}{ Mausund is not part of the PSMSL-database } & Not used \\
\hline Ålesund & 1945 & $95 \%$ & $1981-1983$ & 3 \\
\hline Måløy & 1944 & $93 \%$ & $1960,1978-1980$ & 3 \\
\hline Bergen & 1916 & $92 \%$ & $1971,1973-1975,1988$ & 2 \\
\hline Stavanger & 1919 & $95 \%$ & 1970-1971,1974 & 2 \\
\hline Tregde & 1928 & $98 \%$ & 1994 & 2 \\
\hline Helgeroa & 1967 & $61 \%$ & $1968-1983,1986$ & Not used \\
\hline Viker & 1991 & $49 \%$ & & Not used \\
\hline Oscarsborg & 1873 & $85 \%$ & $\begin{array}{l}1960,1961,1964 \\
1967-1968,1970 \\
1976-1977,1990\end{array}$ & 1 \\
\hline Oslo & 1886 & $93 \%$ & $1965,1972,1974,1991$ & 2 \\
\hline
\end{tabular}

The QC-column indicates the group each tide gauge belongs to in the quality check

difference series between records from nearby tide gauges, see Figs. S1 to S6 in the Supplementary data. A similar approach as the one used in, e.g., Hogarth et al. (2020) was applied, but we used the NKG2016LU-model (Vestøl et al. 2019; Kierulf et al. 2021) to apply GIA-corrections in order to reduce trends that may be introduced by differences in GIA. We focused on tide gauges with more than $80 \%$ of data available over the period 1960-2020, and these tide gauges were divided into six groups (see Table 1). For all difference series, the scatter of the series is significantly reduced after approximately 1990. This coincides with the transition from manual and analogue data recorders to digital and automated decoders. It is clear from the difference series that change in technology has led to a significant quality improvement, reducing the number of anomalous differences, and reducing the number of years of missing data. Differences that deviate more than $50 \mathrm{~mm}$ from the mean are quite common before 1990, but there are only a few differences that are larger than $100 \mathrm{~mm}$. The largest anomalies are found in the early 1960s and involve the tide gauges in Kabelvåg and Ålesund. For the difference series involving Kabelvåg, we also identify a shift in the zero level of magnitude $50-100 \mathrm{~mm}$ around 1990. For the other series, the zero level appears to be constant. In 
subsequent analysis, we will therefore refrain from using data from Kabelvåg. The final data set includes data from 15 out of 23 tide gauges. See Table 1 for more details and Fig. 1 for an overview of the location of the tide gauges. The tide-gauge records are illustrated in Figs. S7 to S21 in the Supplementary data.

\subsection{Projections of future relative sea level}

To assess sea-level change in the period 2021-2100, we have used regional RSL projections of the twenty-first century (Simpson et al. 2015, 2017). These projections are largely based on the fifth assessment report (AR5) of the IPCC (Church et al. 2013) and outputs of the Coupled Model Intercomparison Project phase 5 (CMIP5) (Taylor et al. 2012), but with a VLM model calculated by least squares collocation of observations from 92 Norwegian GPS stations and repeated precise spirit levelling (Vest $\varnothing 1$ 2006; Kierulf et al. 2014). The projections include changes in RSL due to mass and dynamical changes on glaciers and ice caps, groundwater changes, steric/dynamic processes in the ocean, crustal displacements, VLM, and gravitational effects on sea level associated with GIA and ocean mass redistribution.

The RSL projections were available for the period 2008 2100 and for the emission scenarios RCP2.6, RCP4.5, and RCP8.5. To join tide-gauge observations and RSL projections, the respective average sea level of the period 2015-2020 was subtracted from both data sets. The combined series for each tide gauge can then be written

$x_{i}=\left\{\begin{array}{l}z_{i}-\bar{z}_{2015-2020} \quad \text { for } \quad t_{i} \leq 2020 \\ \tilde{z}-\overline{\tilde{z}}_{2015-2020} \text { for } \quad 2020<t_{i} \leq 2100\end{array}\right.$

where $z_{i}$ and $\tilde{z}_{i}$ are tide-gauge observations and RSL projections at epoch $t_{i}$, respectively, $\bar{z}_{2015-2020}$ and $\overline{\tilde{z}}_{2015-2020}$ are the average tide-gauge observation and projection over the period 2015-2020, and $x_{i}$ is the joined series consisting of tide-gauge observations until 2020 and projections thereafter. The combined series are illustrated in Fig. 2.

The ensemble of model outputs from the AtmosphereOcean General Circulation Models used to calculate the steric/dynamic component of the projections, have a significant spread. In addition, the other components contributing to the RSL have uncertainties that must be considered when projecting sea level into the future. The projections are, therefore, given as intervals considered to cover $60-100 \%$ of the total possible future outcome for each emission scenario (Church et al. 2013). From the model range, we will here explore five RSL projections. Dependent on location, the projections correspond to -0.22 to $0.05 \mathrm{~m}$ (the 5 th percentile of $\mathrm{RCP} 26$ ), -0.06 to $0.20 \mathrm{~m}$ (the mean of RCP2.6), 0.02 to $0.28 \mathrm{~m}$ (the median of RCP4.5), 0.20 to $0.46 \mathrm{~m}$ (the mean of RCP8.5), and 0.41 to $0.66 \mathrm{~m}$ (the 95th percentile of RCP8.5) RSL rise by 2081-2100 relative to 2015-2020. The 95th percentile of RCP8.5 is especially important because this scenario is recommended for coastal planning in Norway (DSB 2016).

\subsection{Meteorological reanalysis}

Meteorological processes drive sea-level variability by redistributing water masses and heat in the ocean. Over longer time scales, the sea surface will adjust as an inverted barometer to variation in the atmospheric pressure, i.e., it will rise (fall) in response to a drop (increase) in local atmospheric pressure. Winds influence the sea surface height both locally and remotely (Woodworth et al. 2010), by piling up water as it blows over the surface and by driving ocean circulations that contain sea-level variability on short and long space and time scales (Pugh and Woodworth 2014). Variations in atmospheric pressure and wind have previously been found to be important explanatory variables along the Norwegian coast. Richter et al. (2012) reported that the inverted barometric effect of the atmospheric pressure is responsible for more than half of the explained variability in tide-gauge records along the Norwegian coast. Also, they calculated a correlation of 0.19 between wind and sea-level residuals for monthly data low pass filtered with a 1 year running mean, and they suggested that wind may partly cause the seasonal cycle in sea level along the Norwegian coast.

To reduce effects of wind stress and atmospheric pressure in the sea-level observations, we will use ERA5 reanalysis (Hersbach et al. 2020) produced by the European Centre for Medium-Range Weather Forecasts and downloaded from the Copernicus Climate Change Service (C3S) Climate Data Store. The ERA5 reanalysis has a spatial resolution of $30 \mathrm{~km}$ and are available from 1950 to present. From ERA5, we have used monthly sea-level pressure, wind speeds, and the east $(u)$ and north $(v)$ wind components at $10 \mathrm{~m}$. Annual averages were calculated from the monthly data in order to combine the meteorological reanalysis with the tidegauge observations. We chose to use the ERA5 reanalysis, instead of observations from meteorological stations close to the tide gauges, because ERA5 covers the study period completely and appears to have more stationary mean and variance than observations from single meteorological stations.

In addition to meteorological reanalysis, also the NAO index (NOAA 2021) was explored as explanatory variable. The NAO is a shift in the wintertime position for the North Atlantic storm tracks (Chepurin et al. 2014) and it is represented by the NAO index, i.e., the difference in atmospheric pressure between the Azores and Iceland. The NAO index is connected to the strength of westerly winds across the North Atlantic (Pugh and Woodworth 2014), 
Fig. 2 Combined series of annual tide-gauge observations (black markers) and RSL projections for RCP2.6 (green dotted line), RCP4.5 (blue dashed line), and RCP8.5 (red solid line). The lines and the shaded areas illustrate the ensemble mean and the ensemble spread (5th and 95th percentiles) of the models, respectively
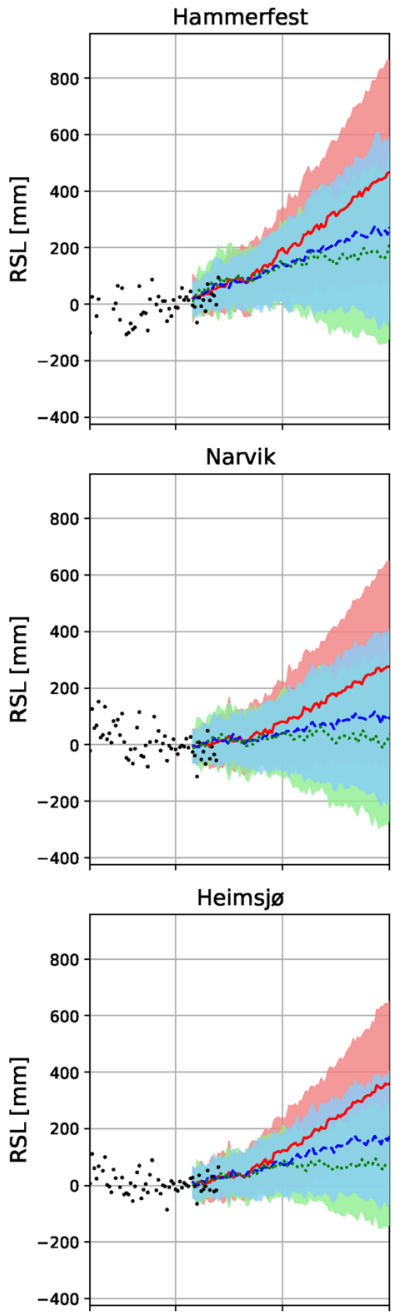

Måıy
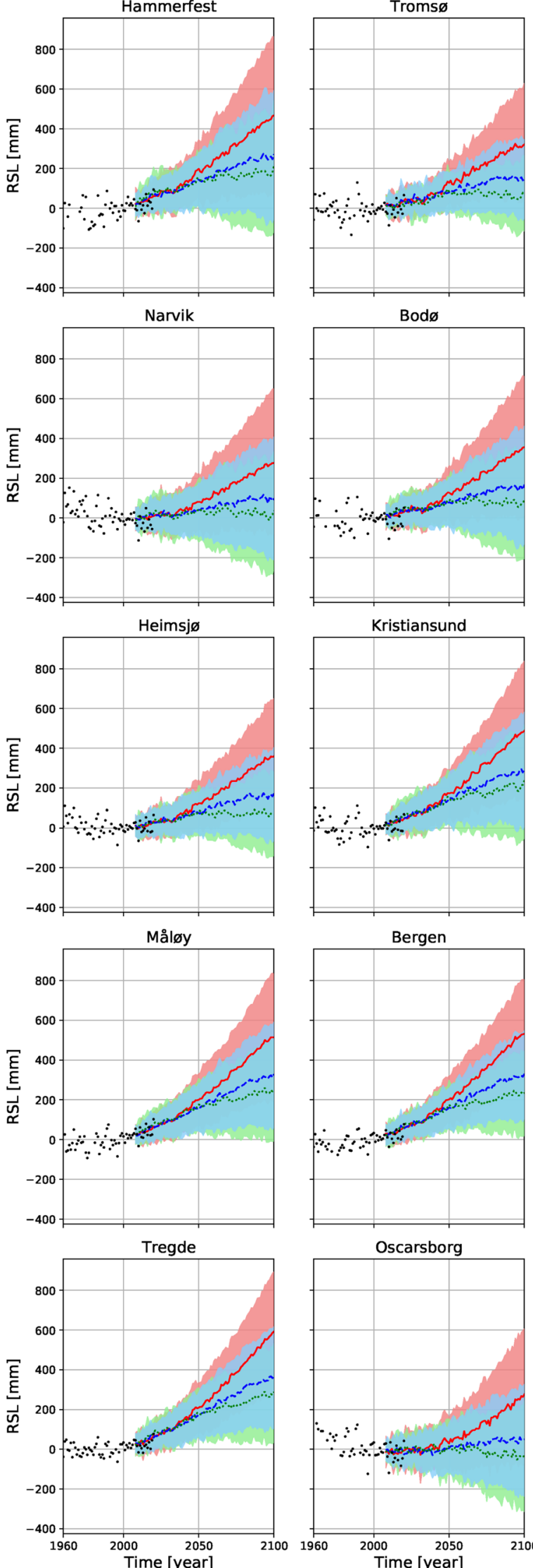

Kristiansund

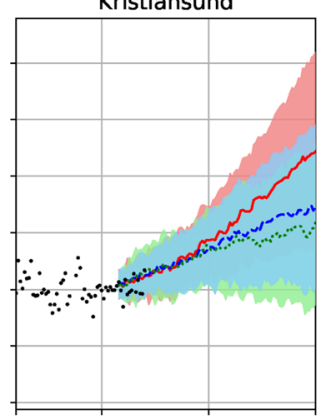

Bergen

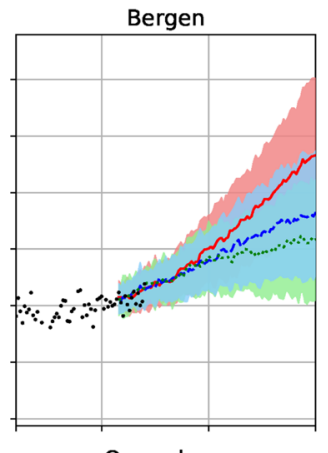

Oscarsborg
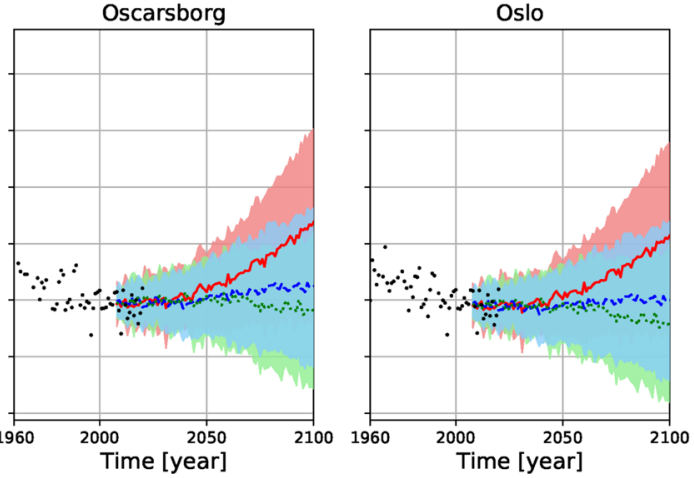
and to atmospheric pressure and temperature distributions worldwide (Kolker and Hameed 2007).

\subsection{Time series analysis and ranking of regression models}

Several previous studies have addressed time-correlated noise in tide-gauge records (see, e.g., Burgette et al. (2013) and Bos et al. (2014)). If not taken into account, time-correlated noise may cause rate estimates with underestimated standard errors. Realistic standard errors and noise characteristics are important in the present study, because they are used to calculate additional noise to the projections and to evaluate the significance of rate and acceleration estimates. When annual tide gauge data are analyzed, the number of observations is small, and Bos et al. (2014) concluded that the first order autoregressive (AR1) noise model yields realistic uncertainties in preference of white noise. Hence, we have used AR1 noise models for regression and for calculating noise series that we will add to the RSL projections.

We created 20 regression models by combining a basic model including only offset and slope with meteorological regressors and the NAO-index (see Table 2). Note that the influence of the nodal cycle of the tides was not investigated, as Breili et al. (2017) found that it has an insignificant effect on tide-gauge observations along the Norwegian coast.

The regression models were fit to each tide-gauge record by a generalized least squares adjustment method implemented in the Python package statsmodels (McKinney et al. 2011). To find the best model at each tide gauge, the models were ranked by Akaike's information criterion (AIC) and the Bayesian information criterion (BIC) for model selection (Akaike 1974; Schwarz 1978) defined in Eqs. 2 and 3.

$$
\begin{aligned}
& \mathrm{AIC}=2 k-2 \ln (\hat{L}) \\
& \mathrm{BIC}=k \ln (n)-2 \ln (\hat{L})
\end{aligned}
$$

Here, $\hat{L}$ is the maximum of the likelihood function for the model, $k$ is the number of estimated parameters, and $n$ is the number of observations. With annual sea-level records starting in 1960 and ending in 2020, the number of observations will be $n \approx 60$ and the number of estimated parameters range from $k=3$ to $k=7$ (including the estimate of $\sigma^{2}$ ). Because the ratio $n / k<40$, we followed the recommendation given by Burnham and Anderson (2002) and used the small sample corrected method, called $\mathrm{AIC}_{\mathrm{C}}$ (Hurvich and Tsai 1989):

$\mathrm{AIC}_{\mathrm{C}}=\mathrm{AIC}+\frac{2 k^{2}+2 k}{n-k-1}$

The ranking of the models was done by calculating $\mathrm{AIC}_{\mathrm{C}}$ and BIC for all model candidates, and for each
Table 2 Regression models fitted to the tide-gauge records

\begin{tabular}{ll}
\hline Model & Definition \\
number & \\
\hline 1 & $z_{i}=\beta_{0}+\beta_{1} t_{i}+\epsilon_{i}$ \\
2 & $z_{i}=\beta_{0}+\beta_{1} t_{i}+\beta_{p} p_{i}+\epsilon_{i}$ \\
3 & $z_{i}=\beta_{0}+\beta_{1} t_{i}+\beta_{p} p_{i}+\beta_{n} n_{i}+\epsilon_{i}$ \\
4 & $z_{i}=\beta_{0}+\beta_{1} t_{i}+\beta_{p} p_{i}+\beta_{w} w_{i}+\epsilon_{i}$ \\
5 & $z_{i}=\beta_{0}+\beta_{1} t_{i}+\beta_{p} p_{i}+\beta_{u} u_{i}+\epsilon_{i}$ \\
6 & $z_{i}=\beta_{0}+\beta_{1} t_{i}+\beta_{p} p_{i}+\beta_{v} v_{i}+\epsilon_{i}$ \\
7 & $z_{i}=\beta_{0}+\beta_{1} t_{i}+\beta_{p} p_{i}+\beta_{n} n_{i}+\beta_{w} w_{i}+\epsilon_{i}$ \\
8 & $z_{i}=\beta_{0}+\beta_{1} t_{i}+\beta_{p} p_{i}+\beta_{n} n_{i}+\beta_{v} v_{i}+\epsilon_{i}$ \\
9 & $z_{i}=\beta_{0}+\beta_{1} t_{i}+\beta_{p} p_{i}+\beta_{n} n_{i}+\beta_{u} u_{i}+\epsilon_{i}$ \\
10 & $z_{i}=\beta_{0}+\beta_{1} t_{i}+\beta_{n} n_{i}+\epsilon_{i}$ \\
11 & $z_{i}=\beta_{0}+\beta_{1} t_{i}+\beta_{n} n_{i}+\beta_{w} w_{i}+\epsilon_{i}$ \\
12 & $z_{i}=\beta_{0}+\beta_{1} t_{i}+\beta_{n} n_{i}+\beta_{u} u_{i}+\epsilon_{i}$ \\
13 & $z_{i}=\beta_{0}+\beta_{1} t_{i}+\beta_{n} n_{i}+\beta_{v} v_{i}+\epsilon_{i}$ \\
14 & $z_{i}=\beta_{0}+\beta_{1} t_{i}+\beta_{w} w_{i}+\epsilon_{i}$ \\
15 & $z_{i}=\beta_{0}+\beta_{1} t_{i}+\beta_{u} u_{i}+\epsilon_{i}$ \\
16 & $z_{i}=\beta_{0}+\beta_{1} t_{i}+\beta_{v} v_{i}+\epsilon_{i}$ \\
17 & $z_{i}=\beta_{0}+\beta_{1} t_{i}+\beta_{u} u_{i}+\beta_{v} v_{i}+\epsilon_{i}$ \\
18 & $z_{i}=\beta_{0}+\beta_{1} t_{i}+\beta_{p} p_{i}+\beta_{u} u_{i}+\beta_{v} v_{i}+\epsilon_{i}$ \\
19 & $z_{i}=\beta_{0}+\beta_{1} t_{i}+\beta_{n} n_{i}+\beta_{u} u_{i}+\beta_{v} v_{i}+\epsilon_{i}$ \\
20 & $z_{i}=\beta_{0}+\beta_{1} t_{i}+\beta_{p} p_{i}+\beta_{i}+\epsilon_{i}$ \\
\hline &
\end{tabular}

$z_{i}, p_{i}, w_{i}, u_{i}, v_{i}$, and $n_{i}$ are the tide-gauge observation, sea-level pressure, wind speed at height $10 \mathrm{~m}$, wind speed in east-direction at $10 \mathrm{~m}$, wind speed in north-direction at $10 \mathrm{~m}$, and the NAO index at epoch $t_{i} . \beta_{0}, \beta_{1}, \beta_{p}, \beta_{w}, \beta_{u}, \beta_{v}$ and $\beta_{n}$ are the regression coefficients to be estimated, i.e., $\beta_{0}$ and $\beta_{1}$ are the intercept and the rate of the model, respectively, $\beta_{p}, \beta_{w}, \beta_{u}, \beta_{v}$, and $\beta_{n}$ are coefficients that connect sea-level pressure, wind speed, and the NAO index to the observations

tide gauge we selected the model with the smallest value of $\mathrm{AIC}_{\mathrm{C}}$ and $\mathrm{BIC}$. With this approach, the fundamental idea is that the model with the smallest value is the one closest to the unknown reality that generated the data, among the candidate models considered (Burnham and Anderson 2002). The regression model-18 (see Table 2), is ranked as best at all tide gauges south of Bodø by both $\mathrm{AIC}_{\mathrm{C}}$ and $\mathrm{BIC}$, except at Oscarsborg where model-6 has a slightly lower BIC. Model-18 includes sea-level pressure and both the north and east wind components. At the northernmost tide gauges (Hammerfest, Harstad, Narvik, and Troms $\varnothing$ ), the ranking is more ambiguous. In all models ranked at top, sea-level pressure and wind components are included, but there are also two tide gauges (Troms $\emptyset$ and Narvik) where the NAO-index is included as regressor in the best-ranked model. Although the ranking is somewhat ambiguous, model-18 will in subsequent analysis be used as the best model along the entire Norwegian coast. We chose this model because it is the model most frequently ranked 
as best, and at stations where it is not ranked as best, it has only a slightly higher $\mathrm{AIC}_{\mathrm{C}}$ and $\mathrm{BIC}$ than the model ranked at top. $\mathrm{AIC}_{\mathrm{C}}$ and $\mathrm{BIC}$ differences for each regression model and each tide gauge are shown in the Supplementary data, Tables $\mathrm{S} 1$ and $\mathrm{S} 2$.

Table 3 lists for each tide gauge the fraction of variance $\left(r_{\text {adj }}^{2}\right)$ explained by the best-ranked model, the percentage reduction of the standard deviation $\left(s 0_{\text {red }}\right)$ after removing variation associated with the meteorological regressors of the best-ranked model, and dominance weights indicating the relative importance of each regressor. The fraction of explained variance ranges from 64.4 to $85.9 \%$ and shows that the best-ranked model at most stations has a good fit to the data. The reduction of the standard deviations varies between 25.6 and $53.8 \%$ and indicates to what extent the noise level of subsequent analysis of the tide-gauge data is reduced by subtracting the signal of the regressors. The dominance weights were computed as the average change in $r_{\text {adj }}^{2}$ when adding the regressor to all possible subsets of the remaining regressors (Tonidandel and LeBreton 2010). From the dominance weights, it is clear that sea-level pressure is the most important regressor, while the effect of including wind speed as regressor varies significantly

Table 3 Dominance weights for sea-level pressure $\left(\Delta r_{\text {slp }}\right)$ and the east $\left(\Delta r_{\mathrm{u}}\right)$ and north $\left(\Delta r_{\mathrm{v}}\right)$ wind speed at $10 \mathrm{~m}$

\begin{tabular}{llllll}
\hline Tide gauge & $\Delta r_{\mathrm{slp}}^{2}$ & $\Delta r_{\mathrm{u}}^{2}$ & $\Delta r_{\mathrm{v}}^{2}$ & $r_{\text {adj }}^{2}$ & $s 0_{\text {red }}$ \\
\hline Hammerfest & 53.2 & 17.9 & -0.5 & 78.2 & 36.4 \\
Troms $\varnothing$ & 43.5 & 9.0 & 11.9 & 64.4 & 34.8 \\
Harstad & 54.4 & 5.5 & 14.6 & 76.8 & 29.6 \\
Narvik & 29.5 & 6.3 & 10.7 & 76.9 & 39.6 \\
Bodø & 47.0 & 19.1 & 12.5 & 80.7 & 41.6 \\
Rørvik & 41.1 & 30.4 & 8.9 & 85.9 & 53.8 \\
Heimsjø & 35.9 & 29.5 & 11.9 & 82.0 & 33.7 \\
Kristiansund & 39.6 & 22.0 & 14.8 & 77.0 & 25.6 \\
Ålesund & 42.8 & 7.3 & 9.7 & 76.7 & 41.8 \\
Måløy & 34.9 & 6.1 & 9.4 & 78.2 & 42.1 \\
Bergen & 36.5 & 10.8 & 15.5 & 78.7 & 31.4 \\
Stavanger & 34.4 & 15.4 & 15.2 & 81.1 & 30.6 \\
Tregde & 38.8 & 13.3 & 9.0 & 66.6 & 26.2 \\
Oscarsborg & 27.2 & 7.8 & 17.7 & 76.0 & 30.6 \\
Oslo & 20.1 & 7.1 & 14.3 & 82.9 & 46.6 \\
\hline
\end{tabular}

The dominance weights indicate the relative importance of each regressor and were computed as the average change in explained variance when adding the regressor to all possible subsets of the remaining regressors. The total fraction of explained variance $\left(r_{\text {adj }}^{2}\right)$ and the percentage reduction of the standard deviation $\left(s 0_{\text {red }}\right)$ when including meteorological regressors in the model are also listed. All numbers are percentages along the Norwegian coast. We did not reveal any strong relationship between the locations of the tide gauges and the calculated $r_{\text {adj }}^{2}, s 0_{\text {red }}$, and dominance weights. Nevertheless, there is a tendency that similar statistics were obtained for neighboring tide gauges and that dominance weights of sea-level pressure increase northward.

\section{Results}

\subsection{Sea-level rates}

We have calculated RSL rates and GIA-corrected sea-level rates for the two study periods 1960-2020 and 19912020, see Table 4. The estimates for the longest period represent sea-level rise over the instrumental record, while the estimates for the shortest period quantify recent sea-level rise. Note that the recent period is coincident with the period with improved data quality revealed by the buddy check.

A similar approach as the one used by Breili et al. (2017) was accomplished for the computations of the rates, but we used annual tide-gauge observations, updated VLM corrections from NKG2016LU (Vestøl et al. 2019; Kierulf et al. 2021), and longer tide-gauge records that include the latest observations. Compared to the VLM-model used in Breili et al. (2017), NKG2016LU is based on an extended set of GNSS and spirit levelling observations and it exploits an underlying GIA-model in the computations. We also applied corrections for the GIA-associated change of the geoid. These corrections were identical to those used by Breili et al. (2017) and were generated from the GIA-model discussed in Simpson et al. (2017). Standard errors of fully GIA-corrected rates were calculated by taking into account the estimated error of the RSL rates (0.3-0.4 mm/year), the observed uncertainty of the VLM corrections $(0.2-0.3 \mathrm{~mm} / \mathrm{year})$, the geoid change error $(0.02-0.04 \mathrm{~mm} /$ year), and the uncertainty in the reference frame's z-drift $(0.5 \mathrm{~mm} /$ year $)$ and scale $(0.3 \mathrm{~mm} /$ year $)$ (Collilieux et al. 2014).

In general, the updated RSL-rates give a similar impression as the rates in Breili et al. (2017) (see Fig. 3). Along the Norwegian coast, the RSL-rates show significant spatial variation due to differences in GIA, i.e., RSL-rates larger than zero can be found along the western and the northern coast of Norway while RSL rates less than zero are found in the middle of Norway and at Oslo and Oscarsborg. Moreover, the spatial variation is strongly reduced by applying GIA-corrections and the GIA-corrected rates are positive at all tide gauges and for both study periods. The coastal average of the GIA-corrected rates is $2.4 \pm$ $0.4 \mathrm{~mm} /$ year and $3.3 \pm 0.4 \mathrm{~mm} /$ year for the periods 1960 2020 and 1991-2020, respectively. Using Welch's unequal 

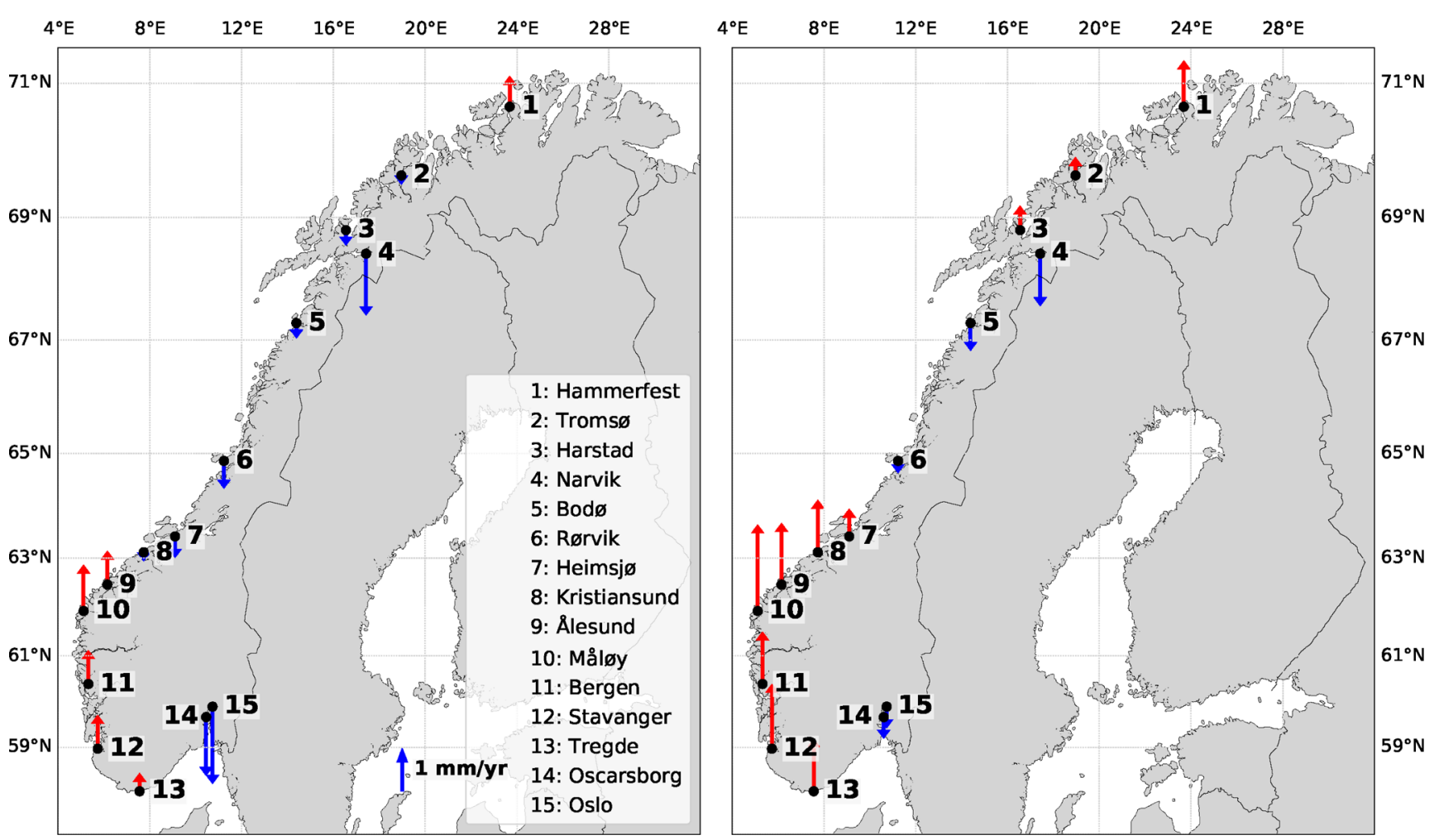

Fig. 3 Observed RSL rates at Norwegian tide gauges for the periods 1960-2020 (left) and 1991-2020 (right)

variances t-test (Welch 1947), we found that the coastal average for the recent period is significantly larger (at the 95\% level) than the average calculated for the instrumental record. This result confirms the increase in sea-level rise between the periods 1960-2010 and 1993-2016 reported by Breili et al. (2017).

Comparison to RSL rates in Breili et al. (2017) reveals also some minor differences. For the instrumental record, the updated RSL rates differ typically less than $0.5 \mathrm{~mm} /$ year, except at Troms $\varnothing$ where the new estimate differs by -0.7 $\mathrm{mm} /$ year. We believe the main reason for the differences is the 10 years of data we have added, as the method of analysis is essentially identical. When it comes to the GIA-corrected rates, we identified differences of up to $0.9 \mathrm{~mm} /$ year. The largest differences where found at tide gauges where the updated VLM-model shows largest changes, i.e., at Harstad, Narvik, Heimsjø, and Kristiansund. Averaged at the location of the tide gauges, the updated VLM-model differ by $0.3 \mathrm{~mm} /$ year, which will propagate directly to the coastal average sea-level rate.

Extending the regression model with meteorological regressors does not change the main impression of the sea-level rates along the Norwegian coast. With the bestranked regression model, the estimated rates are at most tide gauges within the standard error of the rates estimated with the basic model and the coastal averages do not change significantly (Table 4).

\subsection{Detection of accelerating sea-level}

A conventional method for estimating acceleration in data series, is to include a quadratic coefficient in the regression model. When analyzing tide-gauge records, twice the quadratic coefficient will represent the annual change of the sea-level rate. This method has been widely used to estimate accelerating sea level (see, e.g., Jevrejeva et al. (2008), Woodworth et al. (2011), Boon (2012), Haigh et al. (2014), and Veng and Andersen (2021)). As demonstrated by Haigh et al. (2014) and Jevrejeva et al. (2014), estimates of the quadratic coefficient strongly depend on the time period that was analyzed. Therefore, we will here examine all possible sub-records that cover periods longer than 30 years and with all possible start years.

Firstly, a basic regression model including offset, slope, and the quadratic term was tested to estimate acceleration and associated standard errors. The resulting accelerations strongly depend on the length of the study period and the start year, i.e., they alternate around zero and vary between approximately -0.5 and $1.0 \mathrm{~mm} / \mathrm{year}^{2}$ for different study periods. Only a small percentage $(2.7 \%)$ of the estimates is significantly different from zero at the $95 \%$ confidence level. We recalculated the accelerations when including the regressors of the model ranked as best by the $\mathrm{AIC}_{\mathrm{C}}$ and $\mathrm{BIC}$. Also with this model, the estimates strongly depend on the length of the study period and the start year (see Fig. 4). 
Table 4 Observed RSL rates and rates corrected for glacial isostatic adjustment (GIA) at Norwegian tide gauges for the study periods 1960-2020 and 1991-2020

\begin{tabular}{|c|c|c|c|c|}
\hline \multirow[t]{2}{*}{ Tide gauge } & \multicolumn{2}{|l|}{ 1960-2020 } & \multicolumn{2}{|l|}{ 1991-2020 } \\
\hline & $\begin{array}{l}\text { RSL rate } \\
{[\mathrm{mm} / \mathrm{yr}]}\end{array}$ & $\begin{array}{l}\text { GIA-corrected } \\
{[\mathrm{mm} / \mathrm{yr}]}\end{array}$ & $\begin{array}{l}\text { RSL rate } \\
{[\mathrm{mm} / \mathrm{yr}]}\end{array}$ & $\begin{array}{l}\text { GIA-corrected } \\
{[\mathrm{mm} / \mathrm{yr}]}\end{array}$ \\
\hline \multirow[t]{2}{*}{ Hammerfest } & $0.9 \pm 0.4$ & $3.1 \pm 0.7$ & $1.4 \pm 0.7$ & $3.6 \pm 0.9$ \\
\hline & $1.0 \pm 0.5$ & $3.2 \pm 0.8$ & $1.6 \pm 0.7$ & $3.8 \pm 1.0$ \\
\hline \multirow[t]{2}{*}{ Troms $\emptyset$} & $-0.2 \pm 0.4$ & $2.3 \pm 0.7$ & $0.5 \pm 0.5$ & $3.0 \pm 0.8$ \\
\hline & $-0.1 \pm 0.3$ & $2.3 \pm 0.7$ & $0.8 \pm 0.4$ & $3.3 \pm 0.8$ \\
\hline \multirow[t]{2}{*}{ Harstad } & $-0.4 \pm 0.3$ & $2.2 \pm 0.7$ & $0.7 \pm 0.5$ & $3.3 \pm 0.8$ \\
\hline & $-0.2 \pm 0.4$ & $2.4 \pm 0.7$ & $1.0 \pm 0.6$ & $3.6 \pm 0.9$ \\
\hline \multirow[t]{2}{*}{ Narvik } & $-1.9 \pm 0.4$ & $2.1 \pm 0.7$ & $-1.6 \pm 0.6$ & $2.3 \pm 0.8$ \\
\hline & $-1.6 \pm 0.4$ & $2.4 \pm 0.7$ & $-0.8 \pm 0.6$ & $3.2 \pm 0.8$ \\
\hline \multirow[t]{2}{*}{ Bod $\varnothing$} & $-0.4 \pm 0.4$ & $3.0 \pm 0.7$ & $-0.8 \pm 0.6$ & $2.6 \pm 0.9$ \\
\hline & $-0.3 \pm 0.4$ & $3.1 \pm 0.7$ & $-0.2 \pm 0.6$ & $3.2 \pm 0.9$ \\
\hline \multirow[t]{2}{*}{ Rørvik } & $-0.8 \pm 0.4$ & $2.9 \pm 0.7$ & $-0.3 \pm 0.6$ & $3.4 \pm 0.8$ \\
\hline & $-0.6 \pm 0.3$ & $3.0 \pm 0.7$ & $-0.2 \pm 0.6$ & $3.5 \pm 0.9$ \\
\hline \multirow[t]{2}{*}{ Heimsjø } & $-0.6 \pm 0.3$ & $2.2 \pm 0.7$ & $0.8 \pm 0.5$ & $3.6 \pm 0.8$ \\
\hline & $-0.5 \pm 0.4$ & $2.3 \pm 0.7$ & $0.6 \pm 0.7$ & $3.4 \pm 0.9$ \\
\hline \multirow[t]{2}{*}{ Kristiansund } & $-0.2 \pm 0.4$ & $1.7 \pm 0.8$ & $1.6 \pm 0.6$ & $3.5 \pm 0.8$ \\
\hline & $-0.1 \pm 0.6$ & $1.8 \pm 0.8$ & $1.2 \pm 0.8$ & $3.1 \pm 1.0$ \\
\hline \multirow[t]{2}{*}{ Ålesund } & $1.0 \pm 0.3$ & $2.3 \pm 0.7$ & $1.9 \pm 0.6$ & $3.1 \pm 0.8$ \\
\hline & $0.7 \pm 0.3$ & $2.0 \pm 0.7$ & $1.4 \pm 0.7$ & $2.6 \pm 0.9$ \\
\hline \multirow[t]{2}{*}{ Måløy } & $1.4 \pm 0.3$ & $2.5 \pm 0.7$ & $2.7 \pm 0.6$ & $3.8 \pm 0.8$ \\
\hline & $1.1 \pm 0.3$ & $2.2 \pm 0.7$ & $2.1 \pm 0.5$ & $3.2 \pm 0.8$ \\
\hline \multirow[t]{2}{*}{ Bergen } & $1.0 \pm 0.3$ & $2.5 \pm 0.7$ & $1.6 \pm 0.6$ & $3.2 \pm 0.8$ \\
\hline & $0.7 \pm 0.3$ & $2.2 \pm 0.7$ & $1.0 \pm 0.5$ & $2.5 \pm 0.8$ \\
\hline \multirow[t]{2}{*}{ Stavanger } & $1.0 \pm 0.3$ & $2.3 \pm 0.7$ & $2.0 \pm 0.6$ & $3.3 \pm 0.9$ \\
\hline & $0.8 \pm 0.4$ & $2.2 \pm 0.7$ & $1.3 \pm 0.7$ & $2.7 \pm 0.9$ \\
\hline \multirow[t]{2}{*}{ Tregde } & $0.5 \pm 0.3$ & $1.9 \pm 0.7$ & $1.6 \pm 0.7$ & $3.1 \pm 0.9$ \\
\hline & $0.3 \pm 0.3$ & $1.8 \pm 0.7$ & $1.2 \pm 0.8$ & $2.6 \pm 1.0$ \\
\hline \multirow[t]{2}{*}{ Oscarsborg } & $-1.8 \pm 0.5$ & $2.4 \pm 0.8$ & $-0.6 \pm 0.9$ & $3.6 \pm 1.1$ \\
\hline & $-2.2 \pm 0.5$ & $2.0 \pm 0.8$ & $-0.9 \pm 0.5$ & $3.3 \pm 0.8$ \\
\hline \multirow[t]{2}{*}{ Oslo } & $-2.4 \pm 0.4$ & $2.2 \pm 0.7$ & $-0.6 \pm 1.0$ & $4.0 \pm 1.2$ \\
\hline & $-2.7 \pm 0.4$ & $1.9 \pm 0.7$ & $-1.3 \pm 0.6$ & $3.3 \pm 0.8$ \\
\hline \multirow[t]{2}{*}{ Costal average } & & $2.4 \pm 0.4$ & & $3.3 \pm 0.4$ \\
\hline & & $2.3 \pm 0.5$ & & $3.2 \pm 0.4$ \\
\hline
\end{tabular}

For each tide gauge, the first and second line show results obtained with the basic and best-ranked regression model, respectively. The uncertainties for individual estimates are standard errors while the uncertainties for the coastal averages are standard deviations of the rates along the coast

More estimates $(13.2 \%)$ are now significantly different from zero (indicated by black markers in Fig. 4), especially for study periods longer than 40 years. The significant estimates range from -1.1 to $1.0 \mathrm{~mm} / \mathrm{year}^{2}$. For comparison, this range includes estimates that are several times higher than accelerations calculated by Haigh et al. (2014) from individual tide-gauge records over similar study periods. The strong dependency of the study period and the large spread of the estimates imply that any potential climate related change in rate is masked by non-climate related variability that has not been fully accounted for in this study. 

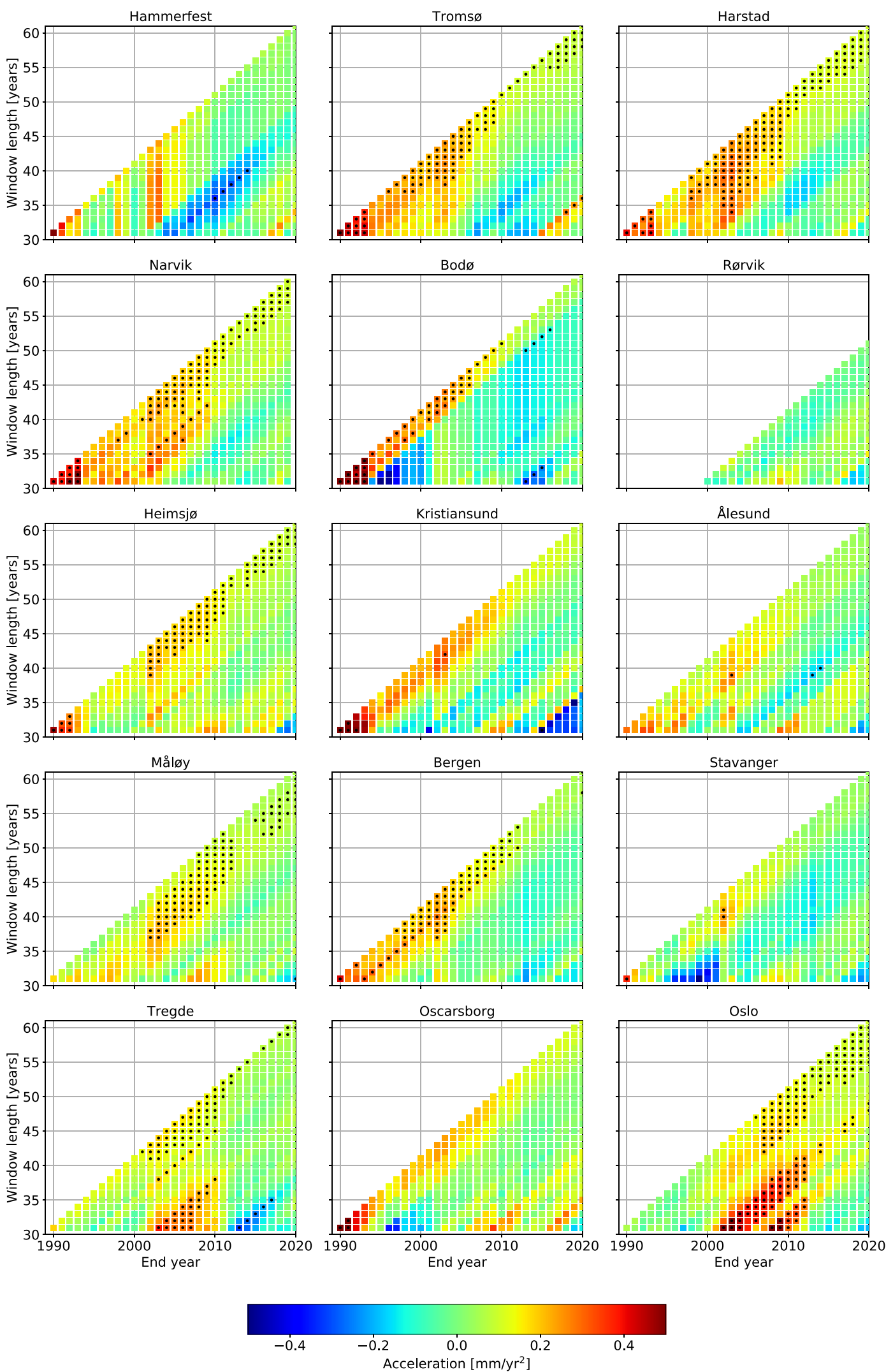

Fig. 4 Accelerations estimated by including quadratic coefficients in the regression model ranked as best by the AIC $\mathrm{C}$ and BIC. Black markers indicate significant estimates at the 95\% confidence level. Only the historical part of the tide-gauge records (1960-2020) was analyzed 


\subsection{Evolution of sea-level rates}

We will here explore Singular-Spectrum Analysis (SSA) as a tool for analyzing non-linear trends in the tide-gauge records. SSA is useful for extracting information from short and noisy time series and provide insight into the dynamics of the underlying system that generated the series (Ghil et al. 2002). The main principle of SSA is to decompose time series into its significant and noisy parts with dataadaptive orthogonal filters (Vautard et al. 1992). The trend of the signal can then be reconstructed from a subset of the significant SSA-components. We consider the trend as a smooth signal filtering out shorter-term natural fluctuations. The main advantages of SSA are that it removes short-lived variability from the time series and provides information of non-linear trends without making assumptions about the nature of the time series prior to the analysis. SSA has been used previously for detecting trends and irregular oscillations in climate time series, including assessments of accelerating sea level (Ghil et al. 2002; Jevrejeva et al. 2006, 2008; Wahl et al. 2011; Dangendorf et al. 2017).

The employed SSA algorithm was based on Golyandina et al. (2001). The first step of the algorithm is to construct a trajectory matrix $(\mathbf{X})$ of lagged copies of the time series $\left(z_{i}\right)$ :

$$
\mathbf{X}=\left[\begin{array}{cccccc}
z_{0} & z_{1} & z_{2} & z_{3} & \ldots & z_{n-m} \\
z_{1} & z_{2} & z_{3} & z_{4} & \ldots & z_{n-m+1} \\
z_{2} & z_{3} & z_{4} & z_{5} & \ldots & z_{n-m+2} \\
\vdots & \vdots & \vdots & \vdots & \ddots & \vdots \\
z_{m-1} & z_{m} & z_{m+1} & z_{m+2} & \ldots & z_{n-1}
\end{array}\right]
$$

The parameter $m$ is called the window length and it controls the resolution of the algorithm. The trajectory matrix can be decomposed with singular-value decomposition, $\mathbf{X}=\mathbf{U} \boldsymbol{\Sigma} \mathbf{V}^{\mathbf{T}}$, where $\mathbf{U}$ and $\mathbf{V}$ contain the left and right singular vectors of $\mathbf{X}$, respectively, and $\boldsymbol{\Sigma}$ contains singular values on the diagonal. From the eigentriples $\left(U_{i}, V_{i}, \sigma_{i}\right)$, elementary matrices $\left(\mathbf{X}_{i}=\sigma_{i} U_{i} V_{i}\right)$ can be formed and a filtered version of the time series can be reconstructed by averaging over the antidiagonals of a small subset of the elementary matrices. In this study, we wanted to reconstruct the trend of the time series and used therefore only the elementary matrix of the first eigentriple. The window length of the algorithm is a compromise between the quantity of information resolved and the degree of statistical confidence in that information (Ghil et al. 2002). We have set $m$ to 15 years, which is identical to the window length used by Dangendorf et al. (2017). To avoid artifacts of the analysis towards the ends of the reconstructed trends, tide-gauge observations prior to the study period (19602020) were included in the SSA where available. For other records, the series were padded by an approach named Monte-Carlo autoregressive padding (Wahl et al. 2010).
From the SSA-components, non-linear trends were reconstructed and non-linear RSL rates were calculated as differences between subsequent points in the trend-series. Although the computed trends are non-linear, we quantified the mean annual change of the RSL rates (acceleration) by fitting linear trends to the rates by least squares adjustment. In order to calculate the uncertainties of the estimates, we used bootstrapping of residuals between the reconstructed trend and the tide-gauge observations. In total, 10000 bootstrap-acceleration estimates were calculated, and the standard error was set equal to the standard deviation of these estimates. We applied SSA to both the raw tidegauge observations and observations corrected for sea-level variation associated with the meteorological regressors of the best-ranked model.

Figure 5 shows the evolution of the RSL rates calculated by differentiating the reconstructed trends. For most of the northern tide gauges (Hammerfest, Troms $\varnothing$, Harstad, Narvik, and Bodø) and several tide gauges in the middle of Norway (Heimsjø, Kristiansund, Bergen, and Stavanger), a similar pattern of variation recurs. That means, there are low rates around 1970, the maximum rates of the study period are found around 1990, and the rates are high thereafter, but with a declining tendency. Also for several of the series where this pattern is not prominent, the maximum rates are found in the late 1990s. This implies that the most recent rates are not higher than rates calculated for previous periods. Removing sea-level variation associated with the meteorological regressors reduces the decadal variation in the rates somewhat, but does not significantly change the overall appearance of the series at most stations. This indicates that the variation in the local atmospheric pressure and the wind speed components are not the main drivers of the multidecadal variability in RSL rates along the Norwegian coast.

From the rate series, mean annual change in the RSL rates over the study periods 1960-2020 and 1991-2020 were calculated (see Table 5 and Fig. 6). For the longest study period (1960-2020), significant positive accelerations appear at most tide gauges, both with raw and corrected observations. The significant accelerations range from 0.021 to $0.059 \mathrm{~mm} / \mathrm{year}^{2}$ and have a standard deviation of $0.02 \mathrm{~mm} / \mathrm{year}^{2}$. For the raw and corrected tide-gauge observations, the coastal average is $0.030 \pm 0.004 \mathrm{~mm} /$ year $^{2}$ and $0.036 \pm 0.005 \mathrm{~mm} / \mathrm{year}^{2}$, which is significantly different from zero and of a magnitude similar to the acceleration of global mean sea level $\left(0.0286 \pm 0.0165 \mathrm{~mm} / \mathrm{year}^{2}\right)$ estimated by Haigh et al. (2014) for the period 1960-2009.

For the recent period 1991-2020, however, significant accelerations were detected at none tide gauges, neither with raw nor corrected observations. Moreover, most of the estimates are less than zero. With raw and corrected data, the coastal average is $0.005 \pm 0.007 \mathrm{~mm} /$ year $^{2}$ and 


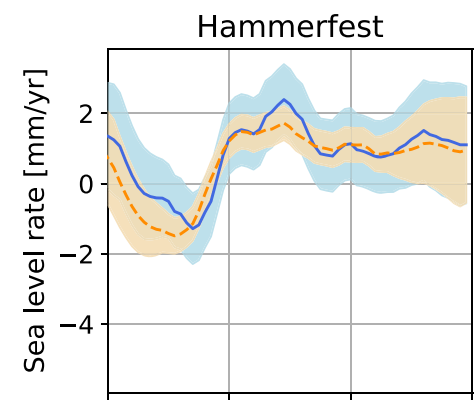

Narvik
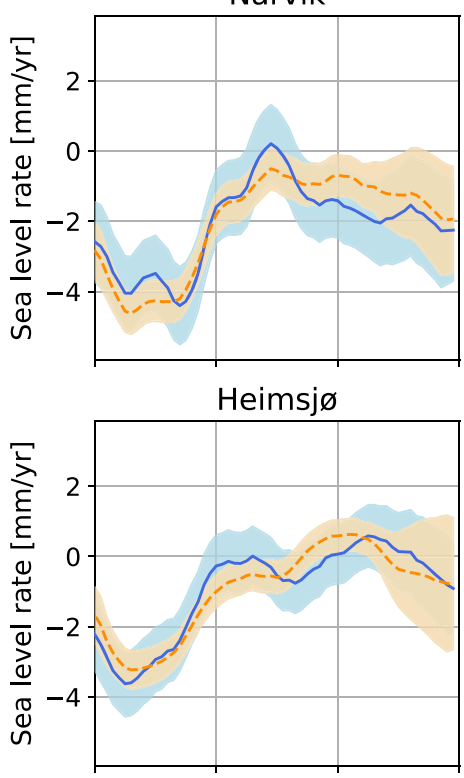

Måløy
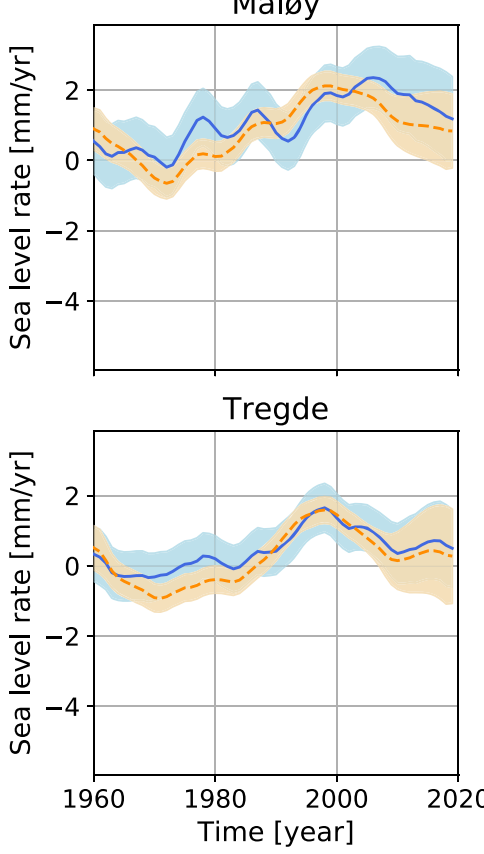

Fig. 5 RSL rates calculated by differentiating trends reconstructed from SSA. Blue lines illustrate rates calculated from raw tide-gauge observations, and orange lines show rates calculated after removing variation associated with the meteorological regressors of the model
Tromsø

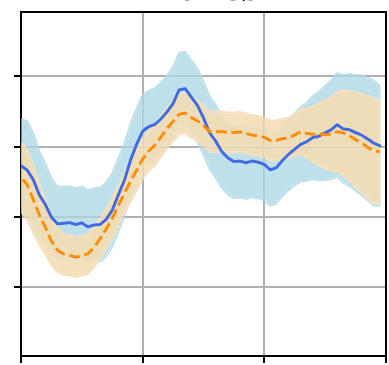

Bodø

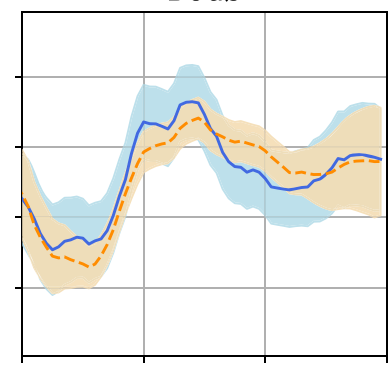

Kristiansund

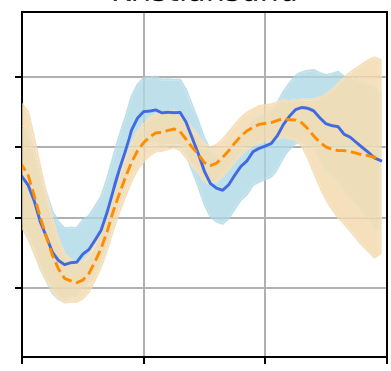

Bergen

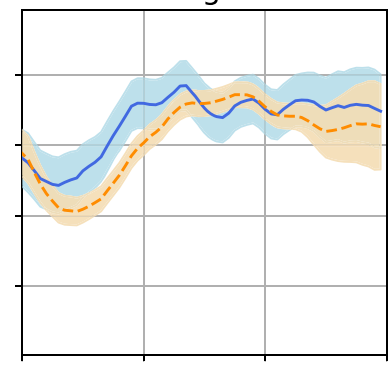

Oscarsborg

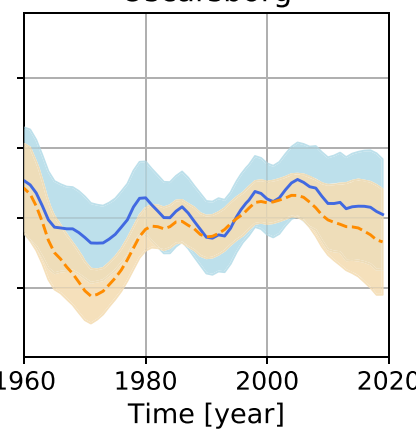

Harstad

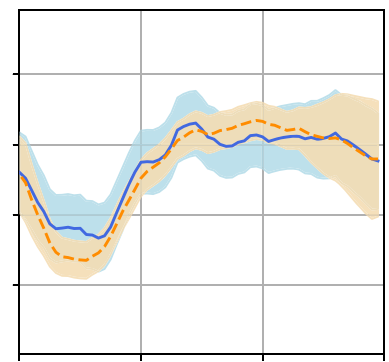

Rørvik

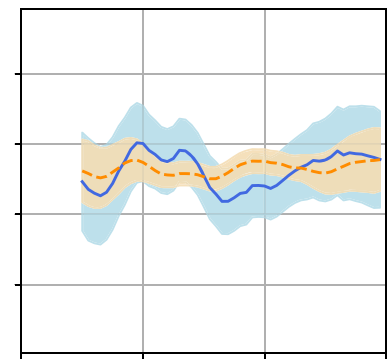

Ålesund

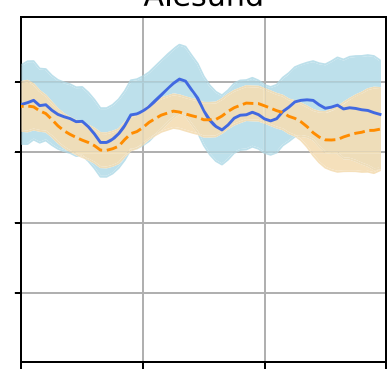

Stavanger

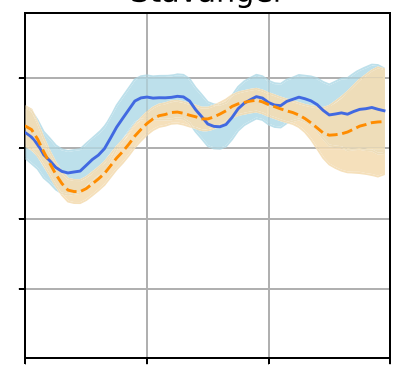

Oslo

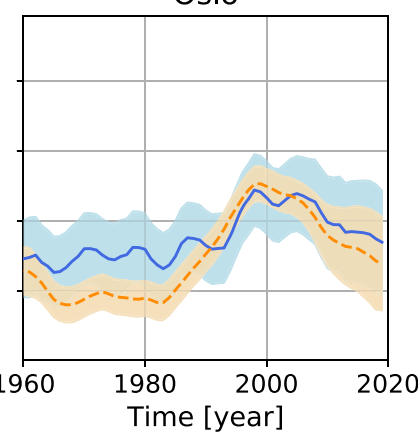

ranked as best by the $\mathrm{AIC}_{\mathrm{C}}$ and BIC. Also shown is the $95 \%$ confidence interval around each line. A window length of 15 years was used in the SSA 
Table 5 Acceleration estimates for the periods 1960-2020 and 19912020 for tide gauges along the Norwegian coast

\begin{tabular}{|c|c|c|}
\hline Tide gauge & $\begin{array}{l}1960-2020 \\
{\left[\mathrm{~mm} / \mathrm{yr}^{2}\right]}\end{array}$ & $\begin{array}{l}1991-2020 \\
{\left[\mathrm{~mm} / \mathrm{yr}^{2}\right]}\end{array}$ \\
\hline Hammerfest & $\begin{array}{l}0.024 \pm 0.015 \\
0.034 \pm 0.012 *\end{array}$ & $\begin{array}{l}-0.001 \pm 0.048 \\
-0.007 \pm 0.035\end{array}$ \\
\hline Troms $\varnothing$ & $\begin{array}{l}0.036 \pm 0.015^{*} \\
0.054 \pm 0.011^{*}\end{array}$ & $\begin{aligned} 0.027 & \pm 0.049 \\
-0.011 & \pm 0.036\end{aligned}$ \\
\hline Harstad & $\begin{array}{l}0.044 \pm 0.013 * \\
0.058 \pm 0.012 *\end{array}$ & $\begin{array}{l}-0.010 \pm 0.041 \\
-0.029 \pm 0.038\end{array}$ \\
\hline Narvik & $\begin{array}{l}0.036 \pm 0.014 * \\
0.058 \pm 0.012 *\end{array}$ & $\begin{array}{l}-0.049 \pm 0.047 \\
-0.040 \pm 0.039\end{array}$ \\
\hline Bod $\varnothing$ & $\begin{array}{l}0.031 \pm 0.015^{*} \\
0.045 \pm 0.013^{*}\end{array}$ & $\begin{array}{l}-0.002 \pm 0.046 \\
-0.034 \pm 0.037\end{array}$ \\
\hline Rørvik & $\begin{array}{l}0.008 \pm 0.020 \\
0.005 \pm 0.012\end{array}$ & $\begin{array}{l}0.053 \pm 0.042 \\
0.009 \pm 0.022\end{array}$ \\
\hline Heimsjø & $\begin{array}{l}0.059 \pm 0.012 * \\
0.055 \pm 0.013^{*}\end{array}$ & $\begin{array}{r}0.003 \pm 0.040 \\
-0.033 \pm 0.042\end{array}$ \\
\hline Kristiansund & $\begin{array}{l}0.050 \pm 0.016^{*} \\
0.055 \pm 0.019^{*}\end{array}$ & $\begin{aligned} 0.042 & \pm 0.051 \\
-0.011 & \pm 0.059\end{aligned}$ \\
\hline Ålesund & $\begin{array}{r}0.004 \pm 0.013 \\
-0.000 \pm 0.009\end{array}$ & $\begin{array}{r}0.016 \pm 0.045 \\
-0.033 \pm 0.029\end{array}$ \\
\hline Måløy & $\begin{array}{l}0.034 \pm 0.011^{*} \\
0.029 \pm 0.008 *\end{array}$ & $\begin{array}{r}0.019 \pm 0.036 \\
-0.036 \pm 0.026\end{array}$ \\
\hline Bergen & $\begin{array}{l}0.036 \pm 0.010^{*} \\
0.043 \pm 0.009 *\end{array}$ & $\begin{array}{r}0.004 \pm 0.032 \\
-0.038 \pm 0.028\end{array}$ \\
\hline Stavanger & $\begin{array}{l}0.025 \pm 0.010 * \\
0.025 \pm 0.010 *\end{array}$ & $\begin{array}{r}0.004 \pm 0.032 \\
-0.028 \pm 0.033\end{array}$ \\
\hline Tregde & $\begin{array}{l}0.021 \pm 0.010^{*} \\
0.024 \pm 0.009 *\end{array}$ & $\begin{array}{r}-0.029 \pm 0.031 \\
-0.048 \pm 0.031\end{array}$ \\
\hline Oscarsborg & $\begin{array}{l}0.011 \pm 0.016 \\
0.021 \pm 0.013\end{array}$ & $\begin{array}{r}0.016 \pm 0.047 \\
-0.016 \pm 0.037\end{array}$ \\
\hline Oslo & $\begin{array}{l}0.028 \pm 0.014 * \\
0.045 \pm 0.010^{*}\end{array}$ & $\begin{array}{l}-0.010 \pm 0.045 \\
-0.053 \pm 0.032\end{array}$ \\
\hline Coastal average & $\begin{array}{l}0.030 \pm 0.004 \\
0.036 \pm 0.005\end{array}$ & $\begin{array}{r}0.005 \pm 0.007 \\
-0.027 \pm 0.004\end{array}$ \\
\hline
\end{tabular}

The standard errors were calculated by bootstrapping residuals between the reconstructed trend and the tide-gauge observations. For each station, the first and second line show results calculated for raw and corrected tide-gauge observations, respectively. Stars indicate estimates that are significantly different from zero at the $95 \%$ level

$-0.027 \pm 0.004 \mathrm{~mm} / \mathrm{year}^{2}$, respectively, of which the latter estimate is significantly less than zero at the $95 \%$ level. This strengthen the impression of declining rates towards the end of the period covered by observations.

\subsection{Time of emergence of significantly higher sea-level rates}

We now aim at identifying the year when sea-level rates are first significantly higher than those observed in the past (prior to 2020). For simplicity, we name this epoch the time of emergence (TOE) and it can be interpreted as the epoch when the sea-level signal of global warming is expected to emerge in the individual tide-gauge records.

To calculate the TOE, we follow a similar method as used by Haigh et al. (2014). With this method, each tide-gauge record is extended until 2100 by RSL projections. Noise is added to the projections in order to generate series with noise properties similar to the observations. For an AR1 noise model, the noise $\varepsilon_{i}$ at epoch $i$ satisfies

$\varepsilon_{i}=\Phi \cdot \varepsilon_{i-1}+w_{i}$,

where $w_{i} \sim N(\sigma)$ (white noise) and $\Phi$ are parameters of the AR1 noise model determined in initial fits to the observations. For each tide gauge, 10000 noise series were simulated and for each time series linear models were fit to consecutive sub-series of lengths 30,40 , and 50 years. The TOE was calculated as the last year of the subseries when the estimated rate was first (and remained) significantly higher than all upper $95 \%$ confidence limits of rates calculated for the period with observations.

For several sea-level pathways, not all 10000 artificially extended tide-gauge records have TOE within the 21st century. For RCP2.6 projections (all study periods) and RCP4.5 (30- and 40-year-long study periods), the majority of the estimated TOEs are beyond 2100. With these combinations of scenarios and study periods, no acceleration can be detected and projected sea level in 2100 can be reached with sea-level rates not significantly higher than those observed in the past. For other RCPs and study periods, Fig. 7 summarizes the distribution of the valid TOE estimates and Table 6 lists the averages of each RCP's median TOE. Note that we have included only results for tide gauges where more than half of the estimated TOEs are within the twenty-first century.

For tide-gauge records extended with RCP4.5 projections and analyzed with 50-year-long study periods, the TOE is within the twenty-first century for half the tide gauges and the median values average to 2058 and 2052 with raw and corrected observations, respectively. Valid TOE estimates are calculated at more stations with records extended with the median of the projection range of RCP8.5. However, it is only with the upper projection range of RCP8.5 that the climate signal will emerge at all tide gauges within the twenty-first century for all study periods. With RCP8.5 and study periods of 50 years, we can expect to observe rates that are significantly higher than observed in the past at the 
Fig. 6 Acceleration estimates with $95 \%$ confidence intervals for the periods 1960-2020 (blue) and 1991-2020 (orange) at tide gauges along the Norwegian coast. The left and right panels show results calculated with raw and corrected tide-gauge observations, respectively
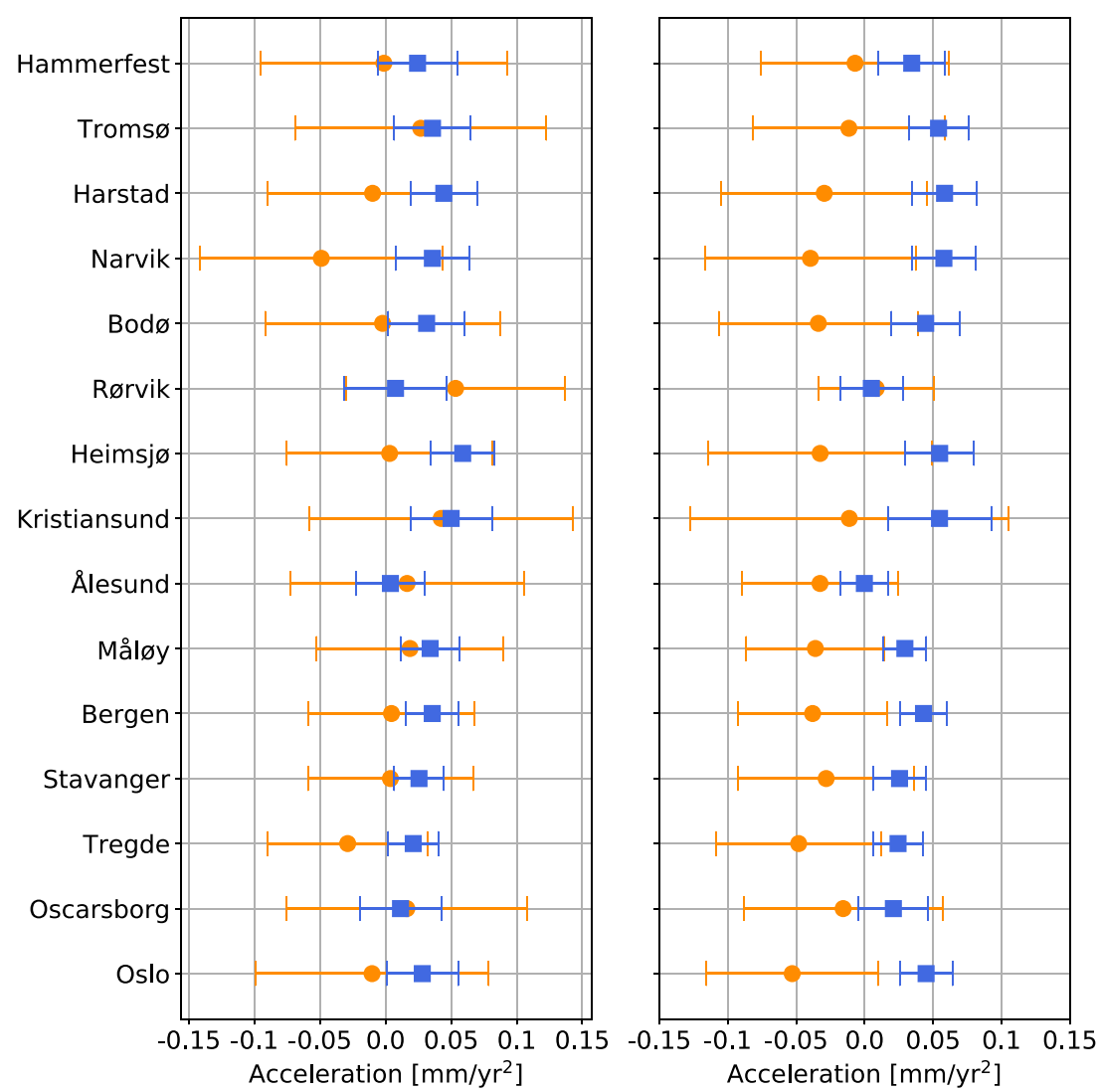

earliest late in the 2030s. With shorter study periods, the TOE will be typically 5 to 15 years later.

At several tide gauges, it appears that earlier TOE will not be obtained by reducing the noise level by subtracting the signal of the meteorological regressors of the best ranked model. This result was unexpected, but arises because serial correlations are introduced when the signal of the meteorological regressors is subtracted. This leads to a larger parameter $\Phi$ of the AR1 model, resulting in turn to rate estimates with larger standard errors. With larger standard errors, the criterion of TOE, i.e., the year when sealevel rates are first significantly higher than those observed in the past, is more difficult to surpass, leading to later TOE. With a white noise model, TOE will occur earlier when reducing the noise level of the record. From Fig. 7, it is also a clear tendency that the TOE occurs earlier when a longer study period is analyzed. This was also reported by Haigh et al. (2014), who detected linear rates earlier when 30- to 40-year-long periods were analyzed in preference of 10- to 20-year-long periods. Two effects can explain this. Firstly, shorter study periods lead to rate estimates with higher standard errors due to fewer observations. This will increase the width of the confidence intervals around both the historic rate estimates and the rate estimates based on projections. Consequently, it will be harder to identify future estimates that are significantly higher than those observed in the past. Secondly, rate estimates based on short study periods are more influenced by decadal variability in the RSL and anomalous observations. This effect may increase the occurrence of high rate estimates in the historic record that future rate estimates must surpass before the TOE is identified.

\section{Discussion}

The window length is a key parameter of the SSA and changing it may influence the reconstructed trends and the derived acceleration estimates. In general, wider window lengths can capture longer periodic variations and leads to reconstructed trends with less detail compared to narrower window lengths. At the same time, high degree of statistical confidence in the reconstructed signal requires a large ratio between the number of observations and the window length (Ghil et al. 2002). With $n$ observations, $n / m<3$ should be avoided (Vautard et al. 1992) and $m$ must be less than $n / 2$. With a window length of 15 years and time series padded with 15 years at both ends, $n / m$ has been between 5.4 and 6.1 in the SSA we have accomplished.

In order to check the effect of the window length, we have done control runs with $m$ set to 10 and 20 years. The most prominent characteristics of the resulting rate-series 

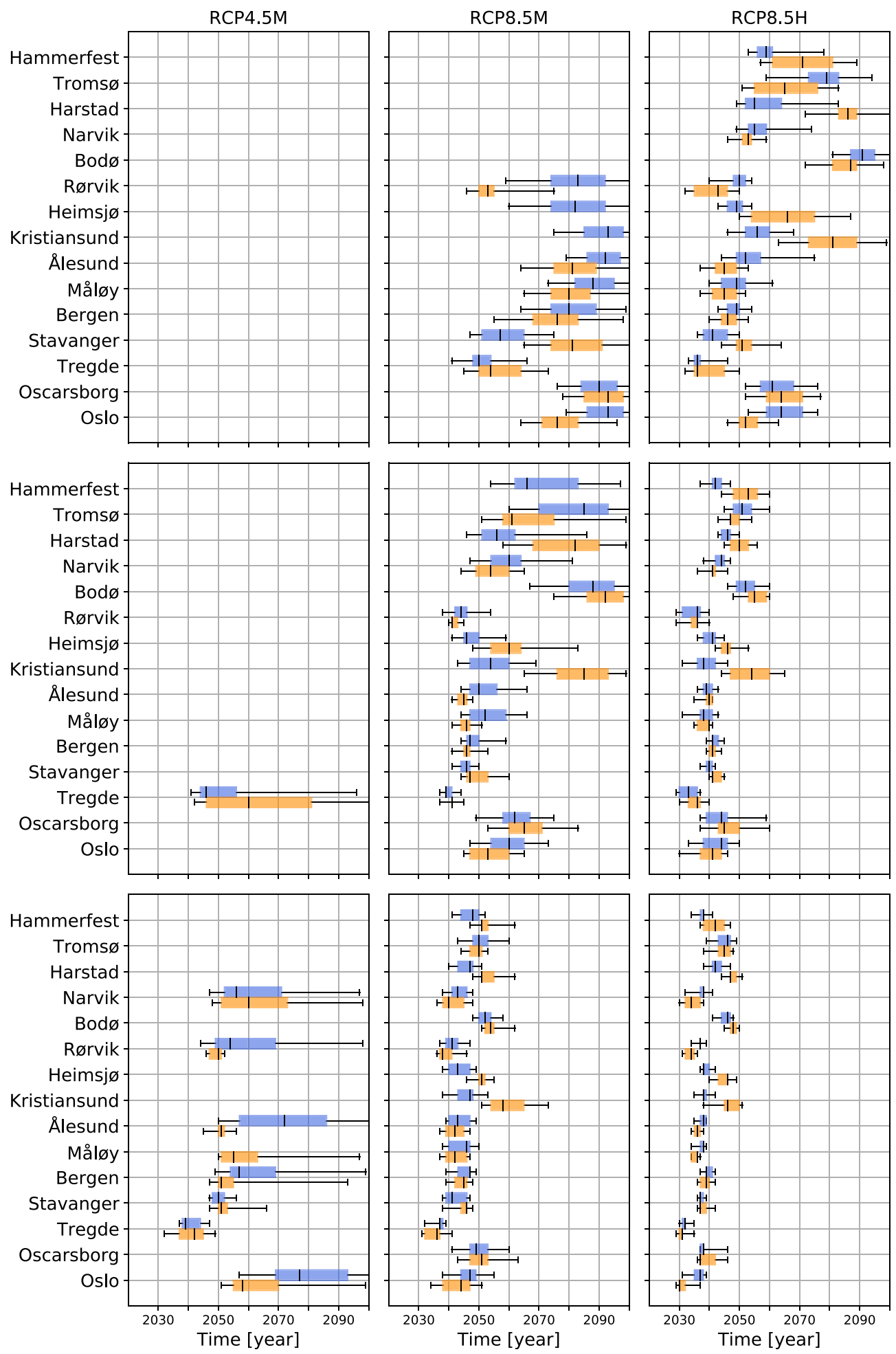

Fig. 7 We have used tide-gauge records extended by RSL projections that were added 10000 different noise series, and calculated the end years of the period when the linear rates are first (and remain) higher than all upper $95 \%$ confidence limits of rates calculated for the observational period (1960-2020). The boxes extend from the lower to the upper quartiles of the estimated end-years, with a line at the median and whiskers that show the range of the data (5th to 95th percentiles). The rates were estimated for consecutive overlapping study periods of
30 (row one), 40 (row two), and 50 years (row three). The left and middle columns show results for tide-gauge records extended with the median of the projection range of RCP4.5 and RCP8.5, respectively, while the right column shows results based on the upper projection range of RCP8.5. For all tide gauges, we have analyzed extended time series based on both raw observations (blue) and observations corrected for variation associated with the meteorological regressors of the best-ranked regression model (orange) 
Table 6 The average of each scenario's median TOE of sea-level change, i.e., the last year of the period when the linear rate was first (and remained) higher than all upper 95\% confidence limits of rates calculated for the period with observations (prior to 2020)

\begin{tabular}{|c|c|c|c|c|c|}
\hline \multirow{2}{*}{$\begin{array}{l}\text { Length of } \\
\text { study period }\end{array}$} & \multicolumn{5}{|c|}{ Time of emergence } \\
\hline & $\mathrm{RCP} 2.6 \mathrm{~L}$ & $\mathrm{RCP} 2.6 \mathrm{M}$ & $\mathrm{RCP} 4.5 \mathrm{M}$ & $\mathrm{RCP} 8.5 \mathrm{M}$ & $\mathrm{RCP} 8.5 \mathrm{H}$ \\
\hline \multirow[t]{2}{*}{$30 \mathrm{yr}$} & $>2100$ & $>2100$ & $>2100$ & $2081(10)$ & $2056(15)$ \\
\hline & $>2100$ & $>2100$ & $>2100$ & $2074(8)$ & $2059(15)$ \\
\hline \multirow[t]{2}{*}{$40 \mathrm{yr}$} & $>2100$ & $>2100$ & $2046(1)$ & $2057(15)$ & $2041(15)$ \\
\hline & $>2100$ & $>2100$ & $2060(1)$ & $2058(14)$ & $2044(15)$ \\
\hline \multirow[t]{2}{*}{$50 \mathrm{yr}$} & $>2100$ & $>2100$ & $2058(7)$ & $2045(15)$ & $2039(15)$ \\
\hline & $>2100$ & $>2100$ & $2052(8)$ & $2047(15)$ & $2039(15)$ \\
\hline
\end{tabular}

For each length of study-period, the first and second line show results based on raw and corrected tide-gauge observations, respectively. The number of tide gauges where more than half of the TOE estimates are within the twenty-first century is indicated in parenthesis for each scenario

consist, i.e., significant decadal and multidecadal variation, a distinct sea-level acceleration between 1970 and 1990 at several tide gauges, and declining rates towards the end of the study period. With $m$ set to 10 years, decadal and multidecadal variation appear to be more short-lived and amplified.

The acceleration estimates calculated from trends reconstructed from SSA with $m$ set to 10 or 20 years, are within the confidence intervals of the reference estimates obtained with $m$ set to 15 years, but with differences reaching approximately $0.015 \mathrm{~mm} /$ year $^{2}$ (see Fig. 8). The deviations from the reference estimates are largest when $m$ is set to 10 years, when uncorrected tide-gauge records are used, and when acceleration is estimated for the recent period 1991-2020. With this setup, the acceleration estimates increase compared to the reference estimate at all tide gauges except Tregde. The increase in acceleration appears to be an effect of the amplified decadal and multidecadal variation that arise due to the shorter window length.

For the longest study period, the coastal averages computed with different window lengths are all within the standard deviation. The general good agreement between the results obtained with different window lengths for the longest study period, makes us confident that the significant accelerations identified by SSA over 1960-2020 represent real changes in the RSL rates and are not artifacts of the analysis. The coastal averages for the shortest study period agree well when corrected tide-gauge observations are used, but turn out to be sensitive to the window length when uncorrected data are used, i.e., the coastal average calculated with $m$ set to 10 years $\left(0.037 \pm 0.010 \mathrm{~mm} /\right.$ year $\left.^{2}\right)$ is significantly different from zero in contrast to the averages calculated with $m$ set to 15 and 20 years that are virtually identical to zero.

For the shortest study period, we also investigated the sensitivity of the acceleration estimates to a 5-year shift in the study period. Breili et al. (2017) showed that a 1 -year shift in the study period can change estimated sealevel rates by more than $1 \mathrm{~mm} /$ year at Norwegian tide gauges. Shifting the study period from 1991-2020 to 19862015 changed the acceleration estimates for single tide gauges by up to $0.08 \mathrm{~mm} / \mathrm{year}^{2}$, and the effect was just as great with corrected as with uncorrected data. Also the coastal averages changed slightly, but coastal averages significantly different from zero were not obtained.

The results from the control runs imply that the acceleration estimates over the short and recent study period are not robust. Also with SSA, the decadal and multidecadal variation in the rate series are significant, and acceleration estimates over short study periods will absorb this variation. We note that the calculated accelerations represent real changes in the sea-level rate, but not necessarily long-term changes in Earth's climate.

Our attempts on using meteorological data led to estimates that appear to be more robust over shorter study periods, but also with corrected tide-gauge observations, significant decadal and multidecadal variation remains. It is therefore pertinent to question if meteorological data and other regressors can be explored more optimum than in the present study. The wind speed reanalysis does not recreate the winds exactly at the locations of the tide gauges and we did not attempt to model effects of wind stress or consider the wind direction relative to the shorelines surrounding the tide gauges. Moreover, the NAO-index was not part of the best ranked regression model. This despite that Chafik et al. (2017) found that anomalous high monthly sea level along the Norwegian coast is predominantly governed by same positive phase type of atmospheric circulation. They suggested that NAO alone is not always sufficient as a forcing mechanism and that the East Atlantic Pattern and the Scandinavian Pattern should be taken into account to explain anomalous periods of sea level. A detailed study of 
Fig. 8 Acceleration estimates calculated for sea-level trends reconstructed from SSA with the window lengths set to 10 (blue squares), 15 (black circles), and 20 (orange triangles) years. The error bars indicate $95 \%$ confidence intervals of the accelerations calculated with a 15-year-long window length. The left and right columns show accelerations for 1960-2020 and 1991-2020, respectively, the upper panels show results based on raw observations, and the lower panels show results based on observations corrected for variation associated meteorological regressors of the best-ranked model
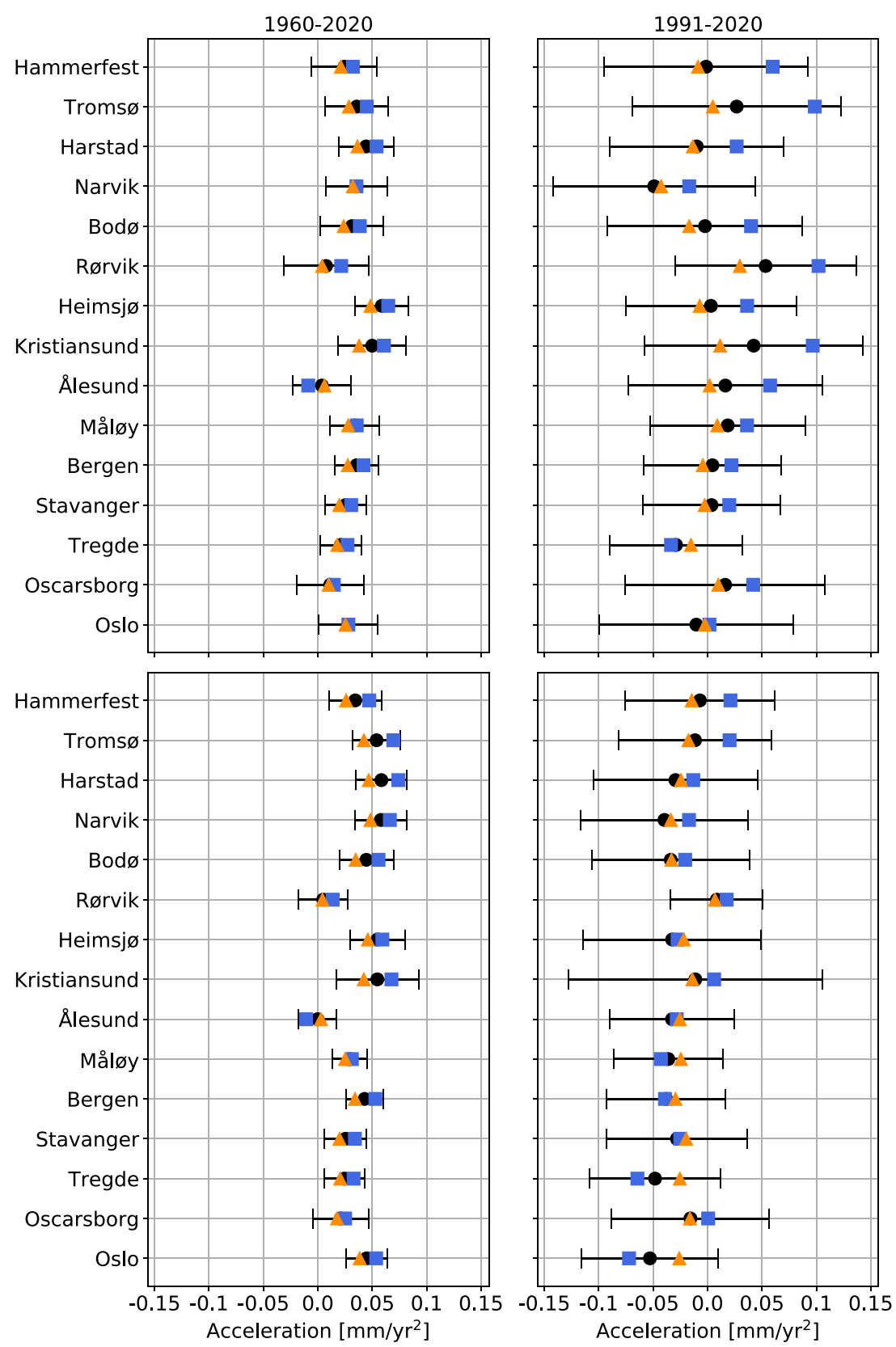

local wind stress and atmospheric circulations influence on Norwegian tide-gauge records should be addressed in later work.

We have not attempted to remove the steric signal from the tide-gauge records, as steric variation is part of climatic sea-level rise. For several stations, the RSL rates increased significantly over the period 1970-1990. This is consistent with Dangendorf et al. (2014) who reported a drop in sea level in the mid-1960s and a maximum at the end of the 1980s for stations around the North Sea. They found high correlation between observed sea level in Stavanger and steric sea level computed from temperature and salinity profiles observed at Sognesjøen in the Norwegian trench. This indicates that a significant fraction of decadal variability of sea level along the Norwegian coast is driven by steric sea level change. Moreover, Dangendorf et al. (2014) demonstrated that this variation is related to remote forcing over the North Atlantic, consistent with the proposed theory of longshore winds that cause coastally trapped waves propagating northward (Calafat et al. 2013). It is reasonable to assume that these processes also contribute to the temporal variations in the RSL rates we have detected. This suggests that the significant increase in RSL rates observed between 1970-1990, is mainly due to decadal variation in the steric component of the RSL. 
The tendency of declining rates after 1991 indicates that the acceleration observed from 1970 to 1990 has not persisted. This implies that sea level along the Norwegian coast has not experienced the same acceleration as observed in records of the global mean sea level over the last 25 years (Nerem et al. 2018; Oppenheimer et al. 2019). Possible explanations for this is that the decadal and multidecadal variation in the Norwegian tide-gauge records mask recent acceleration in sea-level, and that sea-level rise in the North Atlantic can be attributed to a different mix of processes compared to the global mean sea level (Frederikse et al. 2020). A main contributor to non-uniform sea-level rise is mass loss from glaciers and ice sheets (Mitrovica et al. 2001). The ocean mass trend along the Norwegian coast and elsewhere in the subpolar North Atlantic is less than in other ocean basins due to the proximity to the Greenland Ice Sheet (GIS) and regions of glacial mass loss (Frederikse et al. 2020). At the same time, recent acceleration in global mean sea level has been partly attributed to increased mass loss from the GIS. Adopting the language of Oppenheimer et al. (2019), the contribution from the GIS to sea-level rise over 2012-2016 was extremely likely greater than over 19922011. Velicogna et al. (2014) estimated the acceleration in mass loss from the GIS to be $25.4 \pm 1.2 \mathrm{Gt} /$ year $^{2}$ from satellite gravimetric measurements over 2003-2013. This acceleration is equivalent to a sea-level acceleration of approximately $0.07 \mathrm{~mm} / \mathrm{year}^{2}$, i.e., close to the acceleration recently observed in the global mean sea level. The modest contribution from the GIS to sea-level rise along the Norwegian coast, can therefore help explain the absence of acceleration observed in Norwegian tide-gauge records over the period 1991-2020.

Another effect with non-uniform fingerprint on sea level is terrestrial water storage, and Riva et al. (2010) showed that the Norwegian coast is located in one of the regions where the effect on the sea level was largest over the period 2003-2009. Furthermore, a recent study by Hawley et al. (2020) indicated that reservoir constructions after 1900 have moderate or negligible effect on RSL along the Norwegian coast. Still, it is not clear how terrestrial water storage and water impoundment by artificial reservoirs affect sea-level rise along the Norwegian coast over the study periods we have addressed. Finally, we note that the start of the period 1991-2020 was characterized by a reduction in oceanic heat content due to volcano Pinatubo eruption in 1991, lowering the global mean sea level by approximately $6 \mathrm{~mm}$ (Fasullo et al. 2016). This in turn reduced the acceleration of global mean sea level by 0.01 to $0.025 \mathrm{~mm} / \mathrm{year}^{2}$ over the period 1991-2019 (Veng and Andersen 2021). Assuming a similar effect on the sea level along the Norwegian coast, corrected climate driven acceleration over 1991-2020 can be calculated by increasing the estimated accelerations by a similar quantity.

\section{Conclusion}

We have investigated a suite of 20 different regression models and used different techniques to assess accelerating sea level and the evolution of sea-level trends along the Norwegian coast. Initially, the regression models were ranked with the $\mathrm{AIC}_{\mathrm{C}}$ and $\mathrm{BIC}$ for model selection. No single model was ranked as best along the entire coast, but the best-ranked models included sea-level pressure and a wind-component as regressor at all tide gauges. We chose a compromise model including sea-level pressure and the north and east wind components for subsequent analysis along the entire coast.

The first technique applied for detecting acceleration, was to compute updated sea-level rates for the two study periods 1960-2020 and 1991-2020. Comparing the two periods, a significant increase in the coastal average sealevel rate was found. However, we were not able to obtain robust estimates of recent acceleration when including quadratic coefficients in the regression. This appears to be due to decadal and multidecadal variation that dominate Norwegian tide-gauge records and lead to acceleration estimates that strongly dependent on the length and start year of the study period.

We also investigated acceleration in trends reconstructed from SSA. Over the period 1960-2020, we identified significant acceleration in the reconstructed trends at most tide gauges, and we suggest that the acceleration is primarily caused by steric sea-level rise that increased sea-level rates considerably between 1970 and 1990 . SSA indicated that the RSL rate has been high since the 1990s, but with a declining trend at several tide gauges. Furthermore, we did not obtain robust estimates of acceleration over the study period 1991-2020, even though SSA and meteorological corrections reduce decadal variation and the overall noise level of the tide-gauge records considerably. To resolve this, the remaining decadal and multidecadal variability could be identified and accounted for and the study period lengthened to reduce the impact of this variability.

By using tide-gauge records artificially extended by RSL projections until 2100, we have identified the year when estimated sea-level rates are first significantly larger than rates estimated for study periods ending before 2020 . We consider this as a relevant indicator for when the sealevel signal due to global warming will start to emerge at Norwegian tide gauges. For the emission scenario RCP2.6 this happens beyond 2100 , i.e., outside the period covered by the projections. For RCP4.5 and RCP8.5 the climate signal in sea level emerges within the twenty-first century at most tide gauges. For sea-level rise in-line with the upper projection range of RCP8.5, our results suggest that we should expect significantly higher sea-level rates to be observed at first in the late 2030s. Reducing decadal 
variation by taking into account sea-level pressure and wind speed, did not consistently result in earlier TOE. This is because the meteorological corrections introduce serial correlation in the series, leading to rate estimates with enlarged standard errors.

An important implication of the calculated TOEs, is that a possible absence of record high RSL rates in the 2020s, does not falsify that RSL along the Norwegian coast is consistent with RSL projections of the intensive emission scenario RCP8.5.

Supplementary information The online version contains supplementary material available at https://doi.org/10.1007/s10236-021-01492-7.

Acknowledgements The author acknowledges the open access policy of the Permanent Service for Mean Sea Level (PSMSL) and the Copernicus Climate Change Service. The author is indebted to colleagues at the Norwegian Mapping Authority and two anonymous reviewers for most useful comments that helped improve the manuscript.

Funding Open access funding provided by Norwegian University of Life Sciences.

Author contributions $\mathrm{KB}$ conceived the experiments, did all research, prepared the data, accomplished the data analysis, and is the sole author of the paper.

Availability of data and material Tide-gauge records, ERA5 reanalyses, and the NAO-index can be accessed at the Permanent Service for Mean Sea Level (www.psmsl.org, last access: September 2021), the Climate Data Store of the Copernicus Climate Change Service (https://cds.climate.copernicus.eu/cdsapp\#!/home, last access: September 2021), and the National Centers for Environmental Information of the National Oceanic and Atmospheric Administration (https://www.ncdc.noaa.gov/teleconnections/nao/, last access: October 2021), respectively. The GIA-model NKG2016LU can be downloaded from Lantmäteriet.se (https://www.lantmateriet. se/en/maps-and-geographic-information/gps-geodesi-och-swepos/ Referenssystem/Landhojning/, last access: September 2021)

Code availability The regression models were fit and ranked with the Python package statsmodels and we have adopted a Python SSAclass provided at www.kaggle.com (last access: September 2021) for decomposing the tide-gauge records. Prototype scripts for analyzing tide-gauge data are available at https://github.com/brekri/tg_analysis.

\section{Declarations}

Conflict of interest The author declares no competing interests.

Open Access This article is licensed under a Creative Commons Attribution 4.0 International License, which permits use, sharing, adaptation, distribution and reproduction in any medium or format, as long as you give appropriate credit to the original author(s) and the source, provide a link to the Creative Commons licence, and indicate if changes were made. The images or other third party material in this article are included in the article's Creative Commons licence, unless indicated otherwise in a credit line to the material. If material is not included in the article's Creative Commons licence and your intended use is not permitted by statutory regulation or exceeds the permitted use, you will need to obtain permission directly from the copyright holder. To view a copy of this licence, visit http://creativecommons. org/licenses/by/4.0/.

\section{References}

Akaike H (1974) A new look at the statistical model identification. IEEE Trans Automat Control 19(6):716-723. https://doi.org/10. 1109/TAC.1974.1100705

Boon JD (2012) Evidence of sea level acceleration at US and Canadian tide stations, Atlantic Coast, North America. J Coastal Res 28(6):1437-1445. https://doi.org/10.2112/ JCOASTRES-D-12-00102.1

Bos MS, Williams SDP, Araújo IB, Bastos L (2014) The effect of temporal correlated noise on the sea level rate and acceleration uncertainty. Geophys J Int 196(3):1423-1430. https://doi.org/10. 1093/gji/ggt481

Breili K (2021) Dynamic ocean topography from Sentinel-3 and tide gauges along the Norwegian coast (in Norwegian). Kart Plan 81. https://doi.org/10.18261/issn.2535-6003-2021-01-02-04

Breili K, Simpson MJR, Nilsen JEØ (2017) Observed sea-level changes along the Norwegian coast. J Mar Sci Eng 5(29). https:// doi.org/10.3390/jmse5030029

Burgette RJ, Watson CS, Church JA, White NJ, Tregoning P, Coleman $\mathrm{R}$ (2013) Characterizing and minimizing the effects of noise in tide gauge time series: relative and geocentric sea level rise around Australia. Geophys J Int 194:719-736. https://doi.org/10.1093/gji/ ggt131

Burnham KP, Anderson D (2002) Model selection and multimodel inference. A practical information-theoretical approach, 2nd edn. Springer, New York. ISBN:0-387-95364-7

Calafat FM, Chambers DP, Tsimplis MN (2013) Inter-annual to decadal sea-level variability in the coastal zones of the Norwegian and Siberian seas: the role of atmospheric forcing. J Geophys Res-Oceans 118:1287-1301. https://doi.org/10.1002/jgrc.20 106

Cazenave A, Llovel W (2010) Contemporary sea level rise. Annu Rev Mar Sci 2(1):145-173. https://doi.org/10.1146/ annurev-marine-120308-081105

Chafik L, Nilsen JEØ, Dangendorf S (2017) Impact of North Atlantic teleconnection patterns on northern European sea level. J Mar Sci Eng 5(43). https://doi.org/10.3390/jmse5030043

Chepurin GA, Carton JA, Leuliette E (2014) Sea level in ocean reanalyses and tide gauges. J Geophys Res-Oceans 119(1):147155. https://doi.org/10.1002/2013JC009365

Church JA, White NJ (2006) A 20th century acceleration in global sealevel rise. Geophys Res Lett 33(L01602). https://doi.org/10.1029/ 2005GL024826

Church JA, Clark PU, Cazenave A, Gregory JM, Jevrejeva S, Levermann A, Merrifield MA, Milne GA, Nerem RS, Nunn PD, Payne AJ, Pfeffer W, Stammer D, Unnikrishnan AS (2013) Sea level change. In: Stocker T, Qin D, Plattner GK, Tignor M, Allen SK, Boschung J, Nauels A, Xia Y, Bex V, Midgley PM (eds) Climate change 2013: the physical science basis. Contribution of working group I to the fifth assessment report of the intergovernmental panel on climate change. Cambridge University Press, Cambridge, United Kingdom and New York. ISBN:978-1-107-05799-1

Collilieux X, Altamimi Z, Argus DF, Boucher C, Dermanis A, Haines BJ, Herring TA, Kreemer CW, Lemoine FG, Ma C et al (2014) External evaluation of the Terrestrial Reference Frame: report of the task force of the IAG sub-commission 1.2. In: Rizos C, Willis P (eds) Earth on the edge: science for a sustainable planet. Springer, pp 197-202. https://doi.org/10.1007/ 978-3-642-37222-3 25

Dangendorf S, Calafat FM, Arns A, Wahl T, Haigh ID, Jensen J (2014) Mean sea level variability in the North sea: processes and implications. J Geophys Res-Oceans 119:6820-6841. https://doi. org/10.1002/2014JC009901 
Dangendorf S, Marcos M, Wöppelmann G, Conrad CP, Frederikse T, Riva R (2017) Reassessment of 20th century global mean sea level rise. Proc Natl Acad Sci USA 114(23):5946-5951. https://doi.org/ 10.1073/pnas.1616007114

DSB (2016) Havnivåstigning og stormflo - samfunnssikkerhet i kommunal planlegging (in Norwegian). Tech. rep., Direktoratet for samfunnssikkerhet og beredskap, ISBN:978-82-7768-389-8

Fasullo JT, Nerem RS, Hamlington B (2016) Is the detection of accelerated sea level rise imminent? Sci Rep 6(1):2045-2322. https://doi.org/10.1038/srep31245

Frederikse T, Landerer F, Caron L, Adhikari S, Parkes D, Humphrey VW, Dangendorf S, Hogarth P, Zanna L, Cheng L, Wu YH (2020) The causes of sea-level rise since 1900. Nature 584:393-397. https://doi.org/10.1038/s41586-020-2591-3

Ghil M, Allen MR, Dettinger MD, Ide K, Kondrashov D, Mann ME, Robertson AW, Saunders A, Tian Y, Varadi F, Yiou P (2002) Advanced spectral methods for climatic time series. Rev Geophys 40(1). https://doi.org/10.1029/2000RG000092

Golyandina N, Nekrutkin V, Zhigljavsky AA (2001) Analysis of time series structure. SSA and Related Techniques. Chapman and hall/CRC. ISBN 9781584881940

Haigh ID, Wahl T, Rohling EJ, Price RM, Pattiaratchi CB, Calafat FM, Dangendorf S (2014) Timescales for detecting a significant acceleration in sea level rise. Nat Commun 5:3635. https://doi.org/ 10.1038/ncomms4635

Hanssen-Bauer I, EJ Førland, Haddeland I, Hisdal H, Mayer S, Nesje A, Nilsen JEØ, Sandven S, Sandø AB, Sorteberg A, Ådlandsvik B (2017) Climate in Norway 2100-a knowledge base for climate adaptation. Tech. rep., Norwegian Centre for Climate Services (M-741). ISSN 2387-3027

Hartmann DL, Klein Tank AMG, Rusticucci M, Alexander LV, Brönnimann S, Charabi Y, Dentener FJ, Dlugokencky E, Easterling D, Kaplan A, Soden BJ, Thorne PW, Wild M, Zhai PM (2013) Observations: atmosphere and surface. In: Stocker T, Qin D, Plattner GK, Tignor M, Allen SK, Boschung J, Nauels A, Xia Y, Bex V, Midgley PM (eds) Climate change 2013: the physical science basis. Contribution of working group I to the fifth assessment report of the intergovernmental panel on climate change. Cambridge University Press, Cambridge, United Kingdom and New York. ISBN:978-1-10705799-1

Hawley WB, Hay CC, Mitrovica JX, Kopp RE (2020) A spatially variable time series of sea level change due to artificial water impoundment. Earth's Future 8. https://doi.org/10.1029/ 2020EF001497

Hersbach H, Bell B, Berrisford P, Hirahara S, Horányi A, MuñozSabater J, Nicolas J, Peubey C, Radu R, Schepers D, Simmons A, Soci C, Abdalla S, Abellan X, Balsamo G, Bechtold P, Biavati G, Bidlot J, Bonavita M, De Chiara G, Dahlgren P, Dee D, Diamantakis M, Dragani R, Flemming J, Forbes R, Fuentes M, Geer A, Haimberger L, Healy S, Hogan RJ, Hólm E, Janisková M, Keeley S, Laloyaux P, Lopez P, Lupu C, Radnoti G, de Rosnay P, Rozum I, Vamborg F, Villaume S, Thépaut JN (2020) The ERA5 global reanalysis. Q J Roy Meteor Soc 146(730):1999-2049. https://doi.org/10.1002/qj.3803

Hogarth P, Hughes CW, Williams SDP, Wilson C (2020) Improved and extended tide gauge records for the British Isles leading to more consistent estimates of sea level rise and acceleration since 1958. Prog Oceanogr 184:102333. https://doi.org/10.1016/j. pocean.2020.102333

Holgate SJ, Matthews A, Woodworth PL, Rickards LJ, Tamisiea ME, Bradshaw E, Foden PR, Gordon KM, Jevrejeva S, Pugh J (2013) New data systems and products at the permanent service for mean sea level. J Coastal Res 29(3):493-504. https://doi.org/10.2112/ JCOASTRES-D-12-00175.1
Hünicke B, Zorita E (2016) Statistical analysis of the acceleration of Baltic mean sea-level rise, 1900-2012. Front Mar Sci 3(125). https://doi.org/10.3389/fmars.2016.00125

Hurvich CM, Tsai CL (1989) Regression and time series model selection in small samples. Biometrika 76(2):297-307. https://doi. org/10.2307/2336663

Idžanović M, Ophaug V, Andersen OB (2017) The coastal mean dynamic topography in Norway observed by CryoSat-2 and GOCE. Geophys Res Lett 44:5609-5617. https://doi.org/10.1002/ 2017GL073777

Idžanović M, Gerlach C, Breili K, Andersen OB (2019) An attempt to observe vertical land motion along the norwegian Coast by CryoSat-2 and Tide Gauges. Remote Sens 11(7):744. https://doi. org/10.3390/rs11070744

Jevrejeva S, Grinsted A, Moore JC, Holgate S (2006) Nonlinear trends and multiyear cycles in sea level records. J Geophys Res-Oceans 111(C9). https://doi.org/10.1029/2005JC003229

Jevrejeva S, Moore JC, Grinsted A, Woodworth PL (2008) Recent global sea level acceleration started over 200 years ago? Geophys Res Lett 35(8). https://doi.org/10.1029/2008GL033611

Jevrejeva S, Moore JC, Grinsted A, Matthews AP, Spada G (2014) Trends and acceleration in global and regional sea levels since 1807. Global Planet Change 113:11-22. https://doi.org/10.1016/j. gloplacha.2013.12.004

Kierulf HP, Steffen H, Simpson MJR, Lidberg M, Wu P, Wang H (2014) A GPS velocity field for Fennoscandia and a consistent comparison to glacial isostatic adjustment models. J Geophys Res-Solid Earth 119(8):6613-6629. https://doi.org/10. 1002/2013JB010889

Kierulf HP, Steffen H, Barletta VR, Lidberg M, Johansson J, Kristiansen O, Tarasov L (2021) A GNSS velocity field for geophysical applications in Fennoscandia. J Geodyn 146:101845. https://doi.org/10.1016/j.jog.2021.101845

Kolker AS, Hameed S (2007) Meteorologically driven trends in sea level rise. Geophys Res Lett 34(23). https://doi.org/10.1029/ 2007GL031814

Lyu K, Zhang X, Church JA, Slangen ABA, Hu J (2014) Time of emergence for regional sea-level change. Nat Clim Change 4(11):1006-1010. https://doi.org/10.1038/NCLIMATE2397

McKinney W, Perktold J, Seabold S (2011) Time series analysis in python with statsmodels. In: van der Walt S, Millman J (eds) Proceedings of the 10th Python in Science Conference, pp 96-102. https://doi.org/10.25080/Majora-ebaa42b7-014

Mitrovica JX, Tamisiea ME, Davis JL, Milne GA (2001) Recent mass balance of polar ice sheets inferred from patterns of global sea-level change. Nature 409:1026-1029. https://doi.org/10.1038/ 35059054

Nerem RS, Beckley BD, Fasullo JT, Hamlington BD, Masters D, Mitchum GT (2018) Climate-change-driven accelerated sea-level rise detected in the altimeter era. Proc Natl Acad Sci USA 115(9). https://doi.org/10.1073/pnas.1717312115

Nicholls RJ, Cazenave A (2010) Sea-level rise and its impact on coastal zones. Science 328(5985):1517-1520. https://doi.org/10. $1126 /$ science. 1185782

NOAA (2021) National centers for environmental information. North Atlantic Oscillation (NAO). Web portal, retrieved from https:// www.ncdc.noaa.gov/teleconnections/nao/. Accessed June 2021

Ophaug V, Breili K, Andersen OB (2021) A coastal mean sea surface with associated errors in Norway based on new-generation altimetry. Adv Space Res 68(2):1103-1177. https://doi.org/10. 1016/j.asr.2019.08.010

Oppenheimer M, Glavovic BC, Hinkel J, van de Wal R, Magnan AK, Abd-Elgawad A, Cai R, Cifuentes-Jara M, DeConto RM, Ghosh T, Hay J, Isla F, Marzeion B, Meyssignac B, Sebesvari Z (2019) Sea level rise and implications for Low-Lying islands, coasts and 
communities. In: Pörtner HO, Roberts DC, Masson-Delmotte V, Zhai P, Tignor M, Poloczanska E, Mintenbeck K, Alegría A, Nicolai M, Okem A, Petzold J, Rama B, Weyer NM (eds) IPCC special report on the ocean and cryosphere in a changing climate, intergovernmental panel on climate change

Pugh D, Woodworth P (2014) Sea-level science. Understanding tides, surges, tsunamis and mean sea-level changes. Cambridge University Press. ISBN:978-1-107-02819-7

Rhein M, Rintoul SR, Aoki S, Campos E, Chambers D, Feely R, Gulev S, Johnson GC, Josey SA, Kostianoy A, Mauritzen C, Roemmich D, Talley LD, Wang F, Plattner GK (2013) Observations: ocean. In: Stocker T, Qin D, Tignor M, Allen SK, Boschung J, Nauels A, Xia Y, Bex V, Midgley PM (eds) Climate change 2013: the physical science basis. Contribution of Working Group I to the Fifth Assessment Report of the Intergovernmental Panel on Climate Change. Cambridge University Press, Cambridge, United Kingdom and New York. ISBN:978-1-107-05799-1

Richter K, Nilsen JEO, Drange H (2012) Contributions to sea level variability along the Norwegian coast for 1960-2010. J Geophys Res 117(C05038). https://doi.org/10.1029/2011JC007826

Riva REM, Bamber JL, Lavallée DA, Wouters B (2010) Sea-level fingerprint of continental water and ice mass change from GRACE. Geophys Res Lett 37(L19605). https://doi.org/10.1029/ 2010GL044770

Schwarz G (1978) Estimating the dimension of a model. Ann Stat 6(2):461-464

Simpson MJR, Nilsen JEØ, Ravndal OR, Breili K, Sande H, Kierulf HP, Steffen H, Jansen E, Carson M, Vestøl O (2015) Sea level change for Norway: past and present observations and projections to 2100. Tech. rep., Norwegian Centre for Climate Services report 1/2015. ISSN 2387-3025

Simpson MJR, Ravndal OR, Sande H, Nilsen JEØ, Kierulf HP, Vest $\varnothing 1$ O, Steffen H (2017) Projected 21st century sea-level changes, observed sea level extremes, and sea level allowances for Norway. J Mar Sci Eng 5(36). https://doi.org/10.3390/jmse5030036

Taylor KE, Stouer RJ, Meehl GA (2012) An overview of CMIP5 and the experiment design. Bull Am Meteorol Soc 93(4):485-498. https://doi.org/10.1175/BAMS-D-11-00094.1

Tonidandel S, LeBreton JM (2010) Determining the relative importance of predictors in logistic regression: an extension of relative weight analysis. Organ Res Methods 13(4):767-781. https://doi. org/10.1177/1094428109341993
Vautard R, Yiou P, Ghil M (1992) Singular-spectrum analysis: a toolkit for short, noisy chaotic signals. Physica D 58(1-4):95-126. https:// doi.org/10.1016/0167-2789(92)90103-T

Velicogna I, Sutterley TC, van den Broeke MR (2014) Regional acceleration in ice mass loss from Greenland and Antarctica using GRACE time-variable gravity data. J Geophys Res-Space 41:8130-8137. https://doi.org/10.1002/2014GL061052

Veng T, Andersen OB (2021) Consolidating sea level acceleration estimates from satellite altimetry. Adv Space Res 68:496-503. https://doi.org/10.1016/j.asr.2020.01.016

Vestøl O (2006) Determination of postglacial land uplift in Fennoscandia from leveling, tide-gauges and continuous GPS stations using least squares collocation. J Geodesy 80:248-258. https://doi.org/ 10.1007/s00190-006-0063-7

Vestøl O, Ågren J, Steffen H, Kierulf H, Tarasov L (2019) NKG2016LU: a new land uplift model for Fennoscandia and the Baltic Region. J Geodesy. https://doi.org/10.1007/ s00190-019-01280-8

Wahl T, Jensen J, Frank T (2010) On analysing sea level rise in the German Bight since 1844. Nat Hazard Earth Sys 10:171-179. https://doi.org/10.5194/nhess-10-171-2010

Wahl T, Jensen J, Frank T, Haigh ID (2011) Improved estimates of mean sea level changes in the German Bight over the last 166 years. Ocean Dynam 61(5):701-715. https://doi.org/10.1007/ s10236-011-0383-x

Wahl T, Haigh ID, Dangendorf S, Jensen J (2013) Inter-annual and long-term mean sea level changes along the North Sea coastline. J Coastal Res 65(sp2):1987-1992. https://doi.org/10. 2112/SI65-336.1

Welch BL (1947) The generalization of 'student's' problem when several different population variances are involved. Biometrika 34(1/2):28-35. https://doi.org/10.2307/2332510

Woodworth PL, Pouvreau N, Wöppelmann G (2010) The gyre-scale circulation of the North Atlantic and sea level at Brest. Ocean Sci 6(1):185-190. https://doi.org/10.5194/os-6-185-2010

Woodworth PL, Menéndez M, Roland Gehrels W (2011) Evidence for century-timescale acceleration in mean sea levels and for recent changes in extreme sea levels. Surv Geophys 32(4):603-618. https://doi.org/10.1007/s10712-011-9112-8

Publisher's note Springer Nature remains neutral with regard to jurisdictional claims in published maps and institutional affiliations. 